\title{
评述
}

\section{兽用抗生素在土壤中的环境行为、生态毒性及 危害调控}

\author{
王晓洁 ${ }^{1,2,3}$, 赵蔚 $^{2}$, 张志超 $^{2}$, 程和发 ${ }^{2}$, 陶澍 $^{2}$ \\ 1. 中国科学院广州地球化学研究所, 有机地球化学国家重点实验室, 广州 510640; \\ 2. 北京大学城市与环境学院, 地表过程与模拟教育部重点实验室, 北京 100871 ; \\ 3. 中国科学院大学, 北京 100049 \\ *E-mail: hefac@pku.edu.cn \\ 收稿日期: 2020-08-12; 接受日期: 2020-12-01; 网络版发表日期: 2021-05-27 \\ 国家自然科学基金(批准号: U2006212, 41725015)资助项目
}

\begin{abstract}
摘要 长期以来, 集约化畜禽养殖行业广泛使用抗生素来预防和治疗传染性疾病或促进动物生长, 导致其随畜禽 粪便大量地进入农田土壤中, 造成一系列的生态毒理效应, 以及诱导抗性细菌和抗性基因的产生和增长, 对人类 健康带来潜在威胁. 本文系统综述了兽用抗生素在土壤环境中的迁移和降解行为与机理, 对植物、土壤动物与微 生物的毒性效应, 以及抗生素危害调控方法及其机理。抗生素在土壤中的环境行为主要包括吸附/解吸、微生物 降解与非生物降解, 它们与土壤的理化性质( $\mathrm{pH}$ 、有机质含量等)以及抗生素本身结构和化学性质(官能团、疏水 性等)密切相关. 抗生素对植物、土壤动物与微生物的毒理效应主要取决于抗生素的种类和浓度以及土壤的理化 性质等. 抗生素在堆肥和厌氧消化过程中主要通过微生物降解和水解被去除. 此外, 畜禽粪便中的抗生素还可通 过高温热解的方式被高效地分解. 生物炭和石墨烯基复合材料则可以通过氢键、表面络合、静电作用、离子交 换等作用吸附固定土壤中的抗生素, 调控其危害. 在对当前研究进展总结的基础上, 本文提出了抗生素污染研究 中尚待解决的重要问题, 并对未来的研究方向作出展望.
\end{abstract}

关键词农田土壤, 兽用抗生素, 吸附/解吸, 降解, 生态毒理效应, 危害调控

\section{1 引言}

自改革开放以来，我国畜禽养殖业得到了快速发 展，生产方式也逐步从散养发展为规模化的集约化养 殖. 随着集约化猪、鸡养殖的推广与普及，包括抗生 素在内的兽药被大量使用. 抗生素可以预防和治疗畜 禽的传染性疾病, 并在低剂量时促进动物生长, 在保
护动物健康和降低养殖成本方面发挥了积极作用 ${ }^{[1 \sim 3]}$. 抗生素在畜禽体内不会被完全吸收代谢，除小部分在 组织中残留之外几乎全部随粪便排出体外 ${ }^{[3,4]}$. 畜禽粪 便未经处理或经过堆肥化等过程处理后被广泛用作肥 料还田, 导致残留的抗生素也随之进入农田土壤, 带来 抗生素污染与相应的生态风险.

畜禽粪便和土壤中检出率较高的抗生素类型主要

引用格式: 王晓洁, 赵蔚, 张志超, 等. 兽用抗生素在土壤中的环境行为、生态毒性及危害调控. 中国科学: 技术科学, 2021, 51: 615-636 Wang X J, Zhao W, Zhang Z C, et al. Veterinary antibiotics in soils: Environmental processes, ecotoxicity, and risk mitigation (in Chinese). Sci Sin Tech, 2021, 51: 615-636, doi: 10.1360/SST-2020-0337 
有四环素类、喹诺酮类、磺胺类和大环内酯类(表 $\left.1^{[5 \sim 10]}\right)$, 其主要种类及其分子结构如图1所示. 有学者 对不同畜牧养殖基地的猪、牛和鸡粪便样品进行调 查，结果显示金霉素、土霉素、强力霉素、四环素以 及部分喹诺酮类和磺胺类抗生素均被检出 ${ }^{[5,6]}$. 这些畜 禽粪便中的抗生素浓度可以在有机肥的生产过程中通 过生物降解等途径降低, 但不能被完全去除. 唐春玲等 人 $^{[11]}$ 对上海市销售的 40 种商品有机肥进行调查，结果 显示均有不同浓度的四环素类抗生素被检出. 此外, 在施加畜禽粪肥的农田表层土壤和个别蔬菜中也均检 出了较高含量的土霉素和金霉素 ${ }^{[8,9]}$. 进入土壤环境中 的抗生素经过迁移转化，对植物、土壤动物和微生物 的生长发育和繁殖造成了不同程度的影响，还会诱导 抗性细菌和抗性基因的丰度增加(图2)，继而随着食物 链对人类健康造成潜在威胁. 2019年7月 10 日，农业农 村部发布了《中华人民共和国农业农村部公告第194 号》，决定停止生产、进口、经营、使用部分药物饲 料添加剂，并对相关管理政策作出调整．值得指出的
是，农业农村部并没有提出全面禁止在饲料中添加抗 生素，而是在抗生素的减量替代方面做出相关部署. 随着沿海地区人口密度的增加, 畜昺养殖业蓬勃发展, 抗生素将被继续大量使用，其对生态环境和人类健康 所造成的潜在风险也将一直存在.

因此，深入研究抗生素在土壤中的环境行为、毒 理效应以及危害调控方法对建立有效可行的污控方 案、改善土壤环境和降低生态风险具有重要的意义. 在国内外科研工作者所取得代表性成果的基础上，本 文以土壤中兽用抗生素作用机制的影响因素为主线, 依次综述了抗生素的迁移与降解过程及其作用机理和 对植物、土壤动物、微生物造成的生态毒理效应，并 提出了今后的研究方向和建议, 为进一步探究抗生素 的环境行为、毒理效应及其作用机制和开展生态风险 评价提供参考. 另外, 为了加快建立一套完整、成熟、 高效和可行的抗生素消减方案，本文还综述了好氧堆 肥化、厌氧消化、畜禽粪便炭化和(改性)生物炭与石 墨烯基复合材料对抗生素危害调控的主要进展，并展

表 1 畜禽粪便、有机肥和土壤中不同抗生素的残留量 ${ }^{a}$

Table 1 Residual concentrations of different antibiotics in livestock manure, organic fertilizers, and soils

\begin{tabular}{|c|c|c|c|c|}
\hline 抗生素种类 & 土壤/畜禽粪便 & 检出浓度 (mg/kg) & 检出率 (\%) & 参考文献 \\
\hline \multirow{2}{*}{ 四环素 } & 农田 & bdl $\sim 0.553$ & 88 & [7] \\
\hline & 猪、鸡粪便 & $10.2 \sim 41.5$ & 25 & {$[5]$} \\
\hline \multirow{3}{*}{ 土霉素 } & 农田 & bdl $\sim 0.107$ & 93 & {$[7]$} \\
\hline & 菜地 & $0.44 \sim 1.232$ & ND & [8] \\
\hline & 猪、鸡粪便 & $9.70 \sim 173.2$ & 100 & {$[5]$} \\
\hline \multirow{3}{*}{ 金霉素 } & 农田 & bdl $\sim 0.588$ & 93 & {$[7]$} \\
\hline & 猪、鸡粪便 & $0.60 \sim 24.3$ & 35 & [5] \\
\hline & 菜地 & $0.018 \sim 1.559$ & ND & {$[8]$} \\
\hline 强力霉素 & 猪、鸡粪便 & $8.6 \sim 59.8$ & 30 & [5] \\
\hline 诺氟沙星 & 猪、牛粪便 & $0.001 \sim 0.431$ & 100 & {$[6]$} \\
\hline 环丙沙星 & 同上 & $0.008 \sim 0.649$ & 100 & {$[6]$} \\
\hline 恩诺沙星 & 同上 & $0.002 \sim 0.595$ & 100 & {$[6]$} \\
\hline \multirow{2}{*}{ 磺胺二甲嘧啶 } & 鸡、猪粪便 & $3.3 \sim 24.3$ & 70 & [5] \\
\hline & 猪、牛粪便 & $0.068 \sim 4.80$ & $90 \sim 100$ & {$[6]$} \\
\hline 磺胺甲嘧啶 & 同上 & $0.0047 \sim 4.69$ & 100 & [6] \\
\hline 磺胺甲恶唑 & 同上 & $0.870 \sim 4.17$ & 100 & {$[6]$} \\
\hline 磺胺嘧啶 & 菜地 & $0 \sim 0.007$ & 6.85 & [9] \\
\hline 红霉素 & 有机肥 & $0.009 \sim 0.033$ & ND & [10] \\
\hline 罗红電素 & 同上 & $0.014 \sim 0.033$ & ND & {$[10]$} \\
\hline
\end{tabular}

a) bdl: 检测限以下; ND: 未计算 


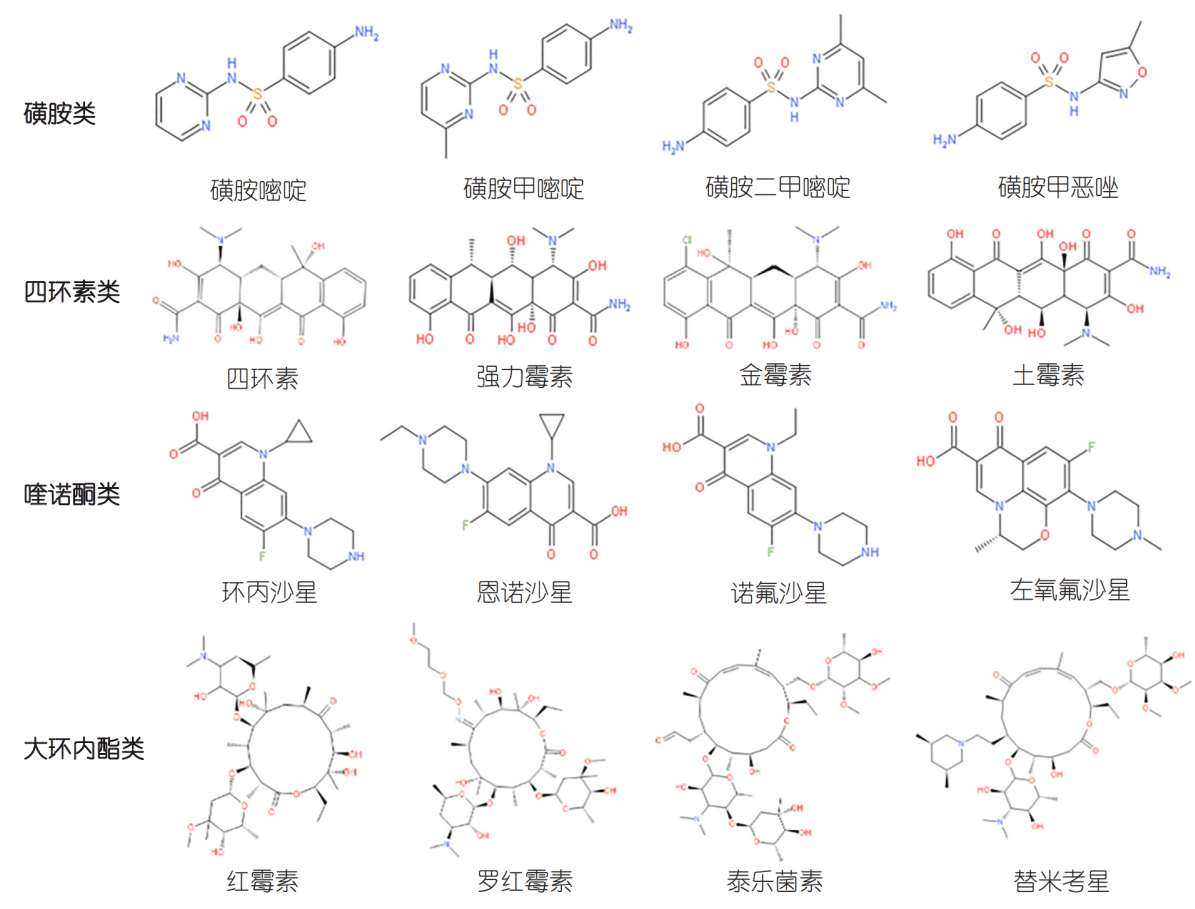

图 1 (网络版彩图)土壤中主要的抗生素类型及其分子结构

Figure 1 (Color online) Main types of antibiotic in soils and their molecular structures.

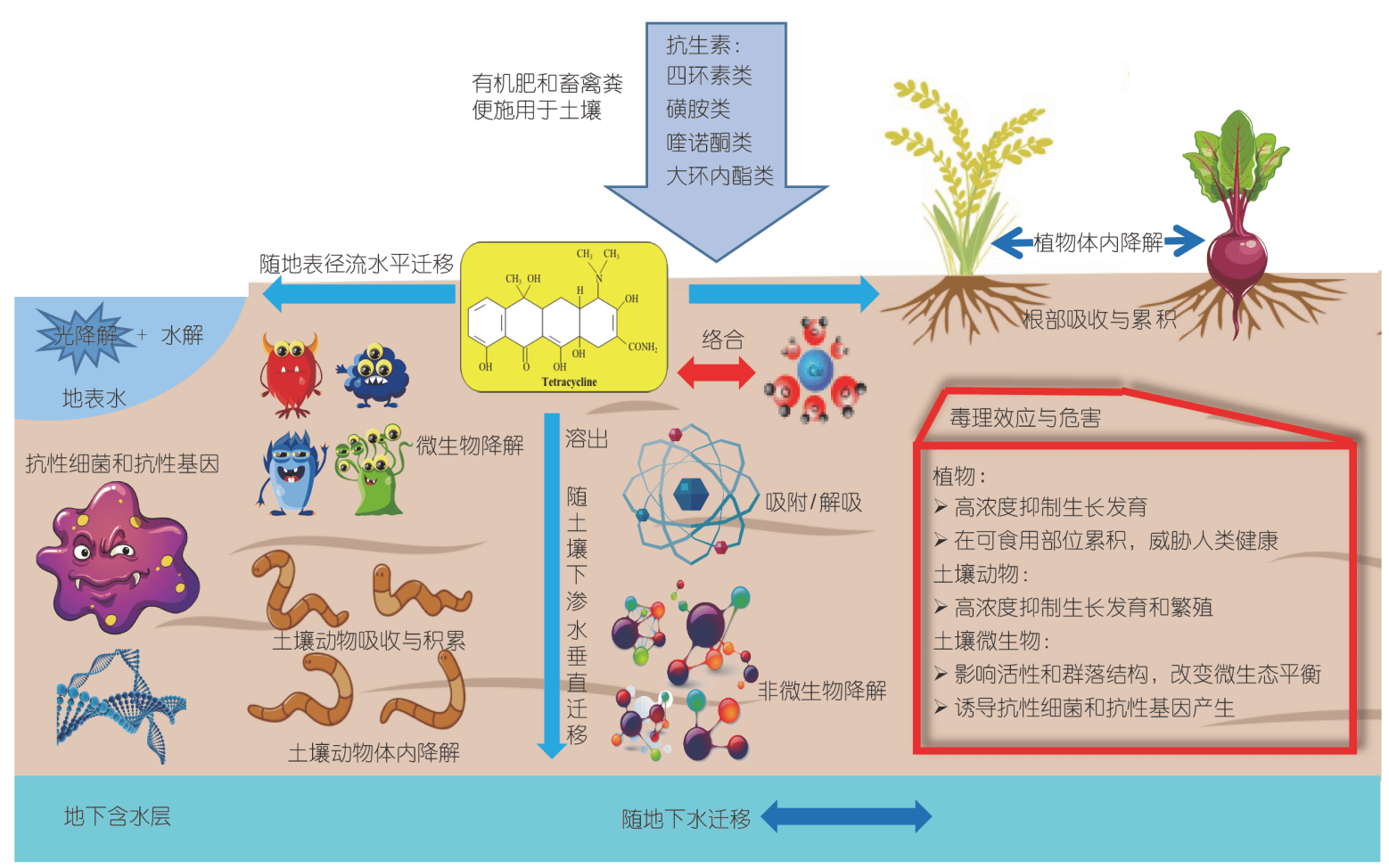

图 2 (网络版彩图)抗生素在土壤中的环境行为和生态毒理效应

Figure 2 (Color online) Environmental behavior and ecotoxicological effects of antibiotic in soil. 
望其未来的发展趋势.

\section{2 土壤中抗生素的迁移与降解机制}

大量的抗生素被持续地排放进入环境中，同时环 境中的抗生素也不断地发生降解转化，使其成为一种 “假”持久性化合物. 抗生素进入土壤后可通过吸附/解 吸、生物和非生物降解等过程在环境介质间迁移与再 分配，这些过程直接影响其在土壤中的“持久性”与生 态毒理效应. 例如, 环丙沙星本身分解较慢, 其半衰期 为三年以上 ${ }^{[12]}$. 而经过 $5 \mathrm{~h}$ 的光照后, 环丙沙星的降解 率接近 $70 \%{ }^{[13]}$. 通常, 抗生素进入土壤后并非经历单一 的迁移与降解过程, 而是多种过程共同进行. 例如, 磺 胺甲恶唑在进入土壤后的 $48 \mathrm{~h}$ 内主要发生吸附，之后 则是微生物降解 ${ }^{[14]}$.

\section{1 吸附/解吸}

吸附/解吸过程对抗生素的迁移、降解以及生物 可利用性都有重要的影响, 是决定抗生素在土壤中环 境行为的关键过程之一 ${ }^{[15]}$. 抗生素在土壤中的吸附机 制通常涉及疏水分配、静电作用、阳离子交换、表面 络合、氢键等一种或多种作用. 一般来说, 抗生素在环 境介质中的吸附性能与自身的理化性质(如空间构 型、官能团、疏水性、吸附系数、离子形态、解离常 数等)密切相关. Huang等人 ${ }^{[16]}$ 观察到不同抗生素在黏 土矿物和土壤中的吸附能力强弱次序为: 四环素类 $>$ 大环内酯类和氟喹诺酮类 $>$ 磺胺类. 氟喹诺酮类、大 环内酯类和四环素类抗生素的吸附系数较高且解吸能 力较低, 可与土壤成分结合形成稳定的残留物 ${ }^{[17 ~ 19]}$, 所以吸附能力较强; 而磺胺类抗生素的吸附系数较低, 在土壤中有很高的迁移能力，较容易迁移到地表或地 下水及周围环境中 ${ }^{[20]}$. 即使化学结构相近, 同一类型 抗生素共存时也会发生竞争吸附，且解吸能力也有所 差异. 例如, Fernández-Calviño等人 ${ }^{[21]}$ 通过竞争吸附实 验比较了四环素、金霉素和土霉素的吸附/解吸性能. 结果表明，在有机碳 $(2.7 \%)$ 、铁氧化物 $(1.3 \mathrm{mg} / \mathrm{g}$ ) 和铝 $(1.5 \mathrm{mg} / \mathrm{g})$ 含量较低的土壤中, 四环素的吸附能力最 强; 解吸强弱顺序为: 四环素 $>$ 金霉素 $>$ 土霉素, 且显 著低于吸附值. Riaz等人 ${ }^{[22]}$ 研究发现 3 种氟喹诺酮类抗 生素在粉砂壤土中的吸附强弱顺序为: 环丙沙星 $>$ 恩 诺沙星 $>$ 左氧氟沙星. 值得注意的是, 上述 3 种氟喹诺
酮类抗生素的解吸能力也有所不同, 其强弱顺序为: 左 氧氟沙星 $>$ 恩诺沙星 $>$ 环丙沙星, 与吸附能力形成对 比, 且解吸值均低于吸附值. Park等人 ${ }^{[23]}$ 认为抗生素 吸附/解吸性能的差异性可能与极化率和分子形态有 关. 此外, 抗生素是一类离子型有机物, 含有多个可解 离的官能团, 包括羰基 $(-\mathrm{CONH}) 、$ 羧酸 $(-\mathrm{COOH}) 、$ 羟 基(-OH)和酰胺 $\left(-\mathrm{NH}\left(\mathrm{CH}_{3}\right)_{2}\right)$ 等，这些官能团可以通过 静电、氢键和络合作用等促使抗生素被吸附到土壤颗 粒表面. 抗生素的解吸量低于吸附量, 这主要与解吸延 滞现象和观测时间密切相关 ${ }^{[21]}$.

土壤的物理化学性质(如 $\mathrm{pH}$ 、有机质、阳离子交 换能力、黏土成分等)均会影响抗生素的吸附/解吸性 能. Fernández-Calviño等人 ${ }^{[21]}$ 研究发现, 在黏土和矿物 质含量较高的土壤中，四环素、土霉素和金霉素的吸 附/解吸能力也相对较高. 天然土壤具有广泛的 $\mathrm{pH}$, 多 种抗生素会以阳离子、两性离子和阴离子的形式存 在, 因此土壤pH对抗生素的吸附有显著影响 ${ }^{[19]}$. 研究 表明, 当静电作用为抗生素(如磺胺类和大环内酯类) 的主要吸附机制时, $\mathrm{pH}$ 降低会导致主要以阳离子形态 分布的抗生素的吸附增强; 而当多种机制(如阳离子交 换、表面络合和阳离子桥联)参与吸附时，抗生素(如 四环素类和氟喹诺酮类)吸附受 $\mathrm{pH}$ 的影响则不明

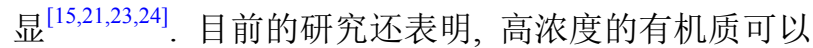
促进土壤中抗生素的解吸 ${ }^{[25]}$, 但对吸附作用的影响仍 存在一些争议. 例如, Kulshrestha等人 ${ }^{[25]}$ 提出土壤中的 有机质可以促进抗生素在土壤中的吸附作用. 而Zhang 等人 ${ }^{[26]}$ 却认为, 由于对吸附位点的竞争，土壤中溶解 性有机质对抗生素的吸附具有抑制作用. 另外, 抗生 素在土壤中的吸附/解吸还受到气候条件(温度、降雨 和湿度)的影响 ${ }^{[14,27]}$, 但相关的研究还很少.

\section{2 微生物降解}

土壤中的微生物在新陈代谢过程中产生的酶可以 对抗生素的分子结构造成破坏, 从而使其发生降解, 这 对抗生素在环境中的转化产生重要影响. 具备降解抗 生素功能的微生物主要为耐药细菌, 它们主要通过取 代基氧化、取代基裂解、取代、羟基化/去羟基化、 水解等作用机制直接或间接地降解抗生素 ${ }^{[28-30]}$. 目前 已知的抗生素降解酶主要包括氨基糖苷类修饰酶、氯 霉素灭活酶、 $\beta$-内酰胺酶和大环内酯类钝化酶四大 类，它们可以通过水解、磷酸化、甲基化、乙酰化、 
核苷化、开环环氧化等途径修饰或破坏抗生素分子结 构 ${ }^{[30]}$. 之前的研究已经发现白腐真菌不仅可以降解四 环素和土霉素, 还可以降解诺氟沙星和环丙沙星 ${ }^{[31,32]}$. 随着研究工作的深入, 其他能够降解抗生素的物种也 陆续被发现. 例如，Leng等人 ${ }^{[28]}$ 分离出了能够降解四 环素的嗜麦芽单胞菌(Stenotrophomonas)菌株DT1，它 可以通过去除 $\mathrm{N}$-甲基、羰基和胺基官能团的途径对 抗生素进行生物转化. Hirth等人 ${ }^{[33]}$ 从加拿大土壤中分 离出了能够降解磺胺二甲嘧啶的微杆菌(Microbacterium sp.)菌株. 近年来的研究表明, 苍白杆菌属(Ochrobactrum sp.)、双头菌属(Labrys sp.)和戈登氏菌属 (Gordonia sp.) 对磺胺甲恶唑的降解率为 $45.2 \%$ $\sim 62.2 \%{ }^{[34]}$; 而从菜地土壤中分离出的埃希氏菌属 $(E s-$ cherichia sp.)和假丝酵母属(Candida sp.)菌株对强力 霉素的降解率分别高达 $92.52 \%$ 和 $91.63 \%{ }^{[35]}$. 另外, Conn等人 ${ }^{[36]}$ 发现生活废水经过土壤渗滤处理后，污水 中的磺胺甲恶唑等有机污染物浓度降低高达 $90 \%$ ，这 主要与土壤有机质的吸附以及生物转化有关.

大量的研究表明土壤中微生物对抗生素的降解过 程与氧气(影响好氧、厌氧、兼性微生物的生长及相 应的代谢途径)、温度(影响微生物的活性)、 $\mathrm{pH}$ (影响 微生物对营养物质的吸收和生长代谢)和土壤种类与 有机质含量(影响微生物的生长状态以及抗生素的生 物可利用性)密切相关 ${ }^{[17,37 ~ 39]}$. 例如, Engelhardt等人 ${ }^{[40]}$ 比较了非饱和态砂土和粉质黏土中磺胺嘧啶的吸附与 生物降解作用. 结果表明, 粉质黏土更有利于磺胺嘧啶 的吸附, 而其在渗透性高的砂土中生物降解速率更高. 此外, 抗生素的重复处理也可影响其降解速率, 但影响 程度因抗生素的类型不同而有所差异. 例如, 重复向土 壤中添加克拉霉素和红需素, 它们的半衰期分别从

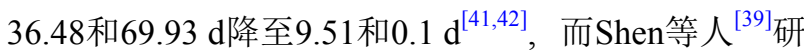
究结果显示, 磺胺嘧啶和磺胺甲恶唑在土壤中导致的 降解不受添加次数的影响. 上述差异可能是因为土壤 中抗生素的降解受到生物和非生物因素的共同影响.

\section{3 非生物降解}

非生物降解主要包括水解、光解和氧化降解, 其 降解机制如图3所示. 水解是土壤中非生物降解抗生 素的重要方式. Volmer等人 ${ }^{[43]}$ 发现 $\beta$-内酰胺类抗生素 因含有 $\beta$-内酰胺环，极易在酸、碱、羟胺及部分金属 离子(铜、铅等)或氧化剂的作用下发生分子重排和水
解而失去抗菌活性. 磺胺类和大环内酯类抗生素也会 发生不同程度的水解，而喹诺酮类抗生素则不容易发 生水解 ${ }^{[37,38]}$. Tang 等人 ${ }^{[44]}$ 研究了不同氨基糖苷类抗生 素的水解能力, 结果显示, 链霉素和大观霉素易发生 水解, 而卡那霉素、庆大霉素和妥布霉素则很难发生 水解反应. 水解作用不仅受到抗生素种类的影响, 还 与环境条件有关. 例如，四环素的水解速率随着 $\mathrm{pH}$ 的 升高而加速 ${ }^{[45]}$. 刘伟等人 ${ }^{[37]}$ 研究表明, 离子强度对抗 生素水解无显著影响，但某些金属离子能够催化水解 和分子重排. Mitchell等人 ${ }^{[46]}$ 则发现螺旋霉素和泰乐 菌素在 $50^{\circ} \mathrm{C} \sim 60^{\circ} \mathrm{C}$ 时水解速率增大, 且温度每升高 $10^{\circ} \mathrm{C}$ 水解速率提升1.5 2.9倍.

光解是土壤中抗生素非生物降解的另外一种重要 途径. 具有吸收光子基团的抗生素分子吸收光能后转 变成激发态进而引发直接光解. 同时, 环境中广泛存 在能够吸收光能呈激发状态后把激发能量传递给受体 分子的光敏剂(如腐殖酸、 $\mathrm{NO}_{3}{ }^{-} 、 \mathrm{NO}_{2}{ }^{-}$等), 受到光敏 剂激发后抗生素可以发生间接光解 ${ }^{[47]}$. 研究表明, 磺 胺类和四环素类抗生素的光解机制主要为间接光解, 而直接光解和间接光解对氟喹诺酮类抗生素的光解都 有贡献 ${ }^{[47,48]}$. 抗生素的种类是影响光解速率的主要因 素. 例如, 表层土壤中氟喹诺酮类抗生素光解很慢, 而 大环内酯类的泰乐菌素、替米考星和四环素类的金霉 素在土壤中可快速降解 ${ }^{[49-51]}$. 另外, 因为在固体表面 存在的能量转移反应、激发态猝灭、光散射以及光屏 蔽作用, 处于吸附状态的抗生素的光化学行为可能与 在水溶液中时完全不同。实验结果表明，相对于在纯 水中, 吸附在高岭土上的环丙沙星光解半衰期增加了 2 25倍 ${ }^{[52]}$, 而当其吸附于蒙脱石上时光解速率增加了 约3 倍 ${ }^{[13]} . \mathrm{Xu}$ 等人 ${ }^{[53]}$ 也证明了吸附于蒙脱石上的四环 素光解速率相比水溶液中增加了 1.1 5.3倍. 高岭土表 面的铝氧八面体上的羟基和环丙沙星的羧基会产生强 烈反应导致光解速率降低，而光照蒙脱石产生的羟基 自由基、单线态氧分别对环丙沙星和四环素光解速率 的增加起到了重要贡献 ${ }^{[13,52,53]}$.

土壤中含有丰富的天然矿物质，这会导致部分抗 生素发生氧化-还原反应. 锰氧化物是土壤和沉积物中 常见的促进有机污染物转化的最重要的天然反应物或 催化剂之一. 研究表明, 氟喹诺酮类抗生素可与水钠锰 矿 $\left(\delta-\mathrm{MnO}_{2}\right)$ 表面的 $\mathrm{Mn}^{4+}$ 形成配合物，在哌嗪环的 $\mathrm{N}_{1}$ 处 产生苯胺基自由基中间体，随后发生 $\mathrm{N}$-脱烷基和C-羟 


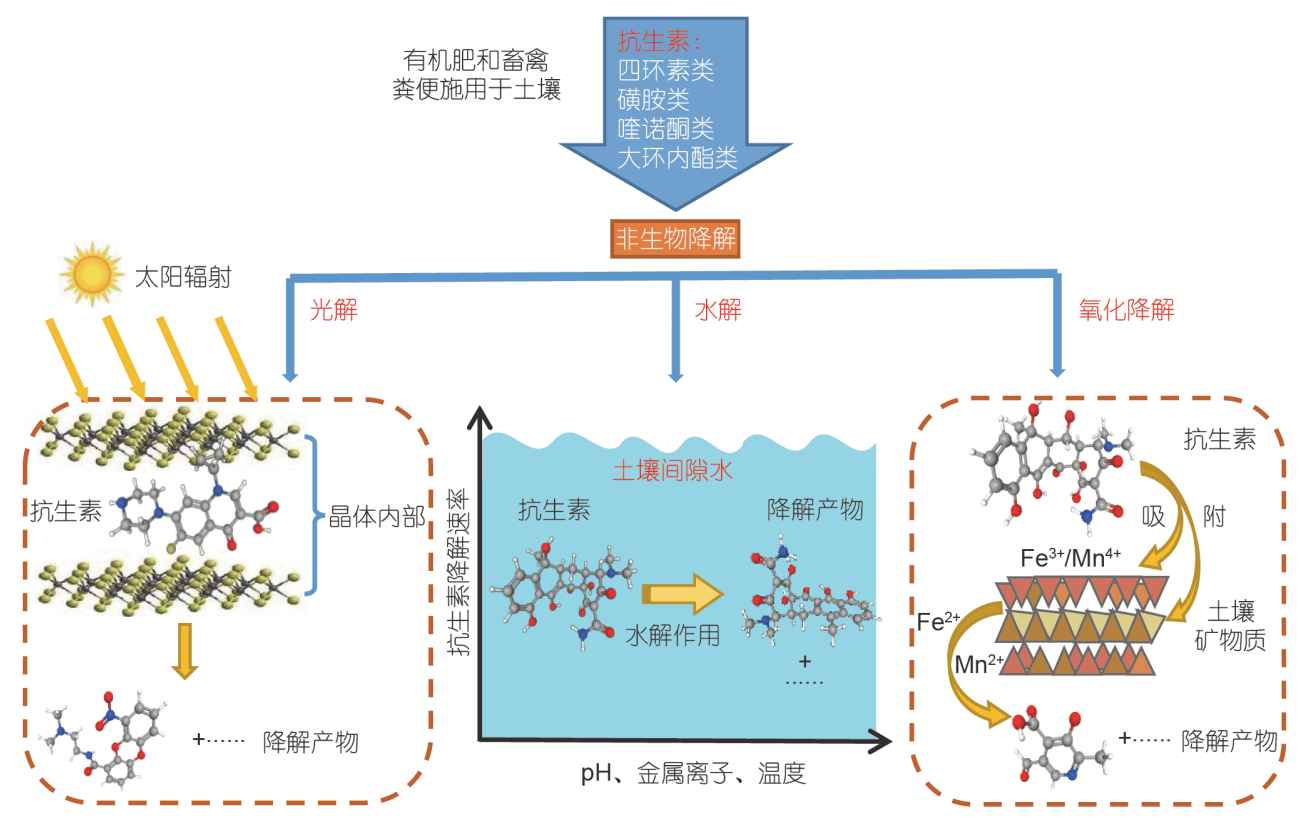

图 3 (网络版彩图)抗生素在土壤中的非生物降解过程 ${ }^{[61 ~ 63]}$

Figure 3 (Color online) Abiotic degradation of antibiotics in soils [61-63].

基化, 最终被降解 ${ }^{[54]}$. Martin等人 ${ }^{[55]}$ 研究发现环丙沙星 可以在赤铁矿 $\left(\gamma-\mathrm{Fe}_{2} \mathrm{O}_{3}\right)$ 表面发生 $\mathrm{N}-$ 脱烷基反应和哌嗪 环开环反应. 天然矿物的催化活性主要取决于其表面 和溶解的金属离子. 例如, Xie等人 ${ }^{[56]}$ 研究结果表明, 硫化亚铁 $(\mathrm{FeS})$ 可以还原四环素，其表面上的 $\mathrm{Fe}^{2+}$ 是吸 附和还原的关键活性位点. $\mathrm{FeS}$ 中的 $\mathrm{S}^{2-}$ 也可直接参与 四环素的降解, 而且作为电子供体促进 $\mathrm{Fe}^{3+} / \mathrm{Fe}^{2+}$ 的循 环，间接加速抗生素的降解. 与氧化降解不同的是，四 环素在 $\mathrm{FeS}$ 表面的降解途径是根据亲电能力逐渐除去 吸电子基团的过程. 值得注意的是, 目前大多数研究是 在水溶液、悬浮液或者泥浆系统中进行的，其中的抗 生素转化过程可能与真实的非饱和态土壤环境有很大 区别 ${ }^{[57]}$. 例如, $\mathrm{Li}$ 等人 ${ }^{[57]}$ 在实验中通过设置蒸发和悬浮 液系统分别模拟自然条件下的非饱和态与饱和态土 壤，研究不同条件下二氧化锰 $\left(\mathrm{MnO}_{2}\right)$ 对磺胺甲恶唑的 氧化降解过程. 结果表明, 与土壤饱和态相比, 非饱和 态条件下 $\mathrm{MnO}_{2}$ 对磺胺甲恶唑的降解速率更高.

抗生素发生非生物降解产生的产物仍可能具有生 态毒性. 研究表明, 螺旋霉素和泰乐菌素的水解产物为 环酯(内酯)基, 具有一定的生物活性, 但低于母体化合 物 ${ }^{[46]}$. 朱昶 ${ }^{[58]}$ 研究结果显示, 四环素和土霉素的光解 产物比母体化合物具有更强的毒性，且与母体化合物
形成联合毒性效应，不仅改变了腿酶和过氧化氢酶的 骨架结构和氨基酸微环境, 还抑制了其催化活性. Jiao 等人 ${ }^{[59]}$ 研究结果表明, 与未经辐照相比, 经光辐照 $4 \mathrm{~h}$ 后的土霉素对发光细菌(Photobacterium phosphoreum) 的发光抑制率增加了 $26 \%$. Halling-Sørensen等人 ${ }^{[60]}$ 探 究了不同 $\mathrm{pH}$ 、金属离子和光照条件下四环素、金霉 素和土霉素降解产物的毒性. 结果表明, 整体上土霉素 和金需素的降解产物的毒性均低于母体化合物; 而四 环素的3种降解产物对抗性菌株均表现出了更高的毒 性，其主要原因可能是降解产物和母体化合物的作用 方式不同. 最近, $\mathrm{Li}^{\text {等人 }}{ }^{[57]}$ 模拟了饱和态和非饱和态 土壤条件下 $\mathrm{MnO}_{2}$ 对磺胺甲恶唑氧化降解产物的毒性 差异. 结果表明, 在非饱和态土壤条件下降解产物的毒 性更高, 对大肠杆菌的生长抑制率也相应增加.

虽然关于抗生素在土壤中的迁移与降解已经开展 了大量的研究工作，但有关非饱和态土壤条件下抗生 素及其降解产物环境行为的研究还很少, 仍处于对相 关机理的认识和探索阶段. 另外，目前的工作大多集 中于针对单一影响因素的研究, 而实际土壤环境非常 复杂, 多种抗生素共存, 抗生素的去除不仅受到自身 化学性质、土壤的理化性质、微生物群落结构甚至气 候方面的多重影响，而且抗生素之间还存在竞争作用， 
这些因素势必对抗生素的迁移与降解造成很大影响.

\section{3 土壤中抗生素的生态毒理效应}

抗生素在土壤中的累积会对植物、土壤动物和微 生物带来毒理效应, 而其在农作物(如蔬菜)可食用部 位的累积会导致食物链的污染，对人体健康带来潜在 的危害. 此外, 进入土壤的抗生素所带来的选择压力 会诱导大量抗性细菌的生长, 并且促进抗性基因在微 生物间发生水平迁移，增加微生物群落的抗性，从而 间接带来公众健康的风险.

\section{1 抗生素对植物生长的毒理效应}

抗生素进入土壤后会影响植物的生长发育, 主要 体现在种子萌发、根长和株高方面. 目前大多数的研 究结果均表明，低浓度抗生素可以促进植物生长，但 在高浓度时对植物生长表现出抑制作用，这与大多数 研究较清楚的有机污染物的效应相似 ${ }^{[64]}$. 如表2所示, 土霉素、四环素、磺胺嘧啶、诺氟沙星、红霉素和氯 霉素对水芹、生菜、番茄、胡萝卜和黄瓜生长发育的
影响均表现为“低促高抑”的特征. Zhang等人 ${ }^{[65]}$ 研究结 果也表明了向土壤中添加低剂量四环素可以促进烟草 生长、株高增加, 而中高剂量四环素的添加对其生长 表现出明显的抑制作用。导致“低促高抑”特征出现的 主要原因是低浓度抗生素可以使植物体内的抗氧化酶 活性增加, 从而清除活性氧自由基保护植物生长; 而当 抗生素超过一定浓度时, 在胁迫机制作用下, 植物体内 会产生过量的活性氧自由基，引起细胞膜膜质的过氧 化和膜结构的破坏，降低了植物体内抗氧化酶的活性, 致使清除自由基的能力下降, 最终对植物生长带来负 面的影响 ${ }^{[66]}$.

抗生素对植物生长发育的影响还与抗生素类型、 植物品种和土壤质地息息相关. Pan等人 ${ }^{[67]}$ 发现 5 种抗 生素对生菜、番茄、胡萝卜和黄瓜的毒性强弱顺序 为: 四环素 $>$ 诺氟沙星 $>$ 红霉素 $>$ 磺胺嘧啶 $>$ 氯霉素, 且生菜对大多数抗生素的敏感性更高. 这些差异可能 与抗生素的疏水性有关, 即疏水性越低, 毒性越强; 而 同一种抗生素对不同植物的毒性作用差异可归因于植 物中的胁迫蛋白谷胱甘肽 $\mathrm{S}$ 转移酶和过氧化物酶的活 性不同 ${ }^{[67]}$. 刘娣 ${ }^{[68]}$ 比较了同一抗生素在4种类型土壤

表 2 抗生素对植物生长发育的毒理效应

Table 2 Toxicological effects of antibiotics on plant growth

\begin{tabular}{|c|c|c|c|c|c|}
\hline 抗生素种类 & 抗生素浓度 $(\mathrm{mg} / \mathrm{kg})$ & 植物类型 & 植物部位 & 影响效果 & 参考文献 \\
\hline \multirow{2}{*}{ 红霉素 } & 0.01 & \multirow{2}{*}{ 生菜、胡萝卜、番茄、黄瓜 } & \multirow{2}{*}{ 芽 } & 促进 & \multirow{2}{*}[67]{} \\
\hline & $0.1 \sim 300$ & & & 抑制 & \\
\hline 金霉素 & $2.5 \sim 20$ & 小白菜 & 芽 & 抑制 & {$[68]$} \\
\hline \multirow{2}{*}{ 土霉素 } & 0.1 & \multirow[t]{2}{*}{ 水芹 } & \multirow[t]{2}{*}{ 株高 } & 促进 & \multirow[t]{2}{*}[69]{} \\
\hline & $0.5 \sim 10$ & & & 抑制 & \\
\hline \multirow{4}{*}{ 四环素 } & 0.01 & \multirow[t]{2}{*}{ 胡夢卜、番茄、黄瓜 } & \multirow[t]{2}{*}{ 芽、根 } & 促进 & \multirow{2}{*}[67]{} \\
\hline & $0.1 \sim 300$ & & & 抑制 & \\
\hline & 5 & \multirow[t]{2}{*}{ 烟草 } & \multirow[t]{2}{*}{ 茎 } & 促进 & \multirow[t]{2}{*}[65]{} \\
\hline & 50,500 & & & 抑制 & \\
\hline \multirow{2}{*}{ 磺胺嘧啶 } & 0.01 & \multirow[t]{2}{*}{ 生菜、番茄、胡萝卜 } & \multirow[t]{2}{*}{ 芽 } & 促进 & \multirow[t]{2}{*}[67]{} \\
\hline & $0.1 \sim 300$ & & & 抑制 & \\
\hline \multirow{2}{*}{ 诺氟沙星 } & 0.01 & \multirow[t]{2}{*}{ 生菜、胡萝卜、番茄 } & \multirow[t]{2}{*}{ 根 } & 促进 & \multirow[t]{2}{*}[67]{} \\
\hline & $0.1 \sim 300$ & & & 抑制 & \\
\hline 磺胺甲恶唑 & $5 \sim 20$ & 黄瓜、生菜 & 根、芽、株高 & 抑制 & {$[70]$} \\
\hline \multirow{2}{*}{ 氯霉素 } & 0.01 & \multirow{2}{*}{ 生菜、番茄、黄瓜 } & \multirow{2}{*}{ 芽 } & 促进 & \multirow[t]{2}{*}[67]{} \\
\hline & $0.1 \sim 300$ & & & 抑制 & \\
\hline
\end{tabular}


中对小白菜根长的抑制效应, 其强弱顺序为: 砖红壤 $>$ 红壤 $>$ 青紫泥 $>$ 黑土, 进一步的分析结果表明, 抗生素 对植物的毒性效应与土壤有机质、氮、磷、钾的含量 和阳离子交换量有关. 此外, 还有研究发现, 与单一抗 生素相比，两种抗生素的复合污染对蔬菜种子萌发、 根长和芽长的影响更大 ${ }^{[66]}$.

目前关于抗生素对植物生长发育的影响已经开展 了很多研究工作, 但大多数仅针对于单一抗生素的毒 性效应。而实际土壤环境中多种抗生素共存，不同抗 生素的复合污染可能对植物造成更大的影响. 另外, 由于受到多重因素的影响，抗生素浓度与毒性效应的 临界值仍然不明确.

\section{2 植物对抗生素的吸收、累积与降解}

暴露于抗生素后，植物可以主动或被动地对抗生 素进行吸收、累积和降解. 一方面，不同植物对抗生 素的响应程度不同。例如，研究表明胡萝卜对阿莫西 林和四环素的吸收量明显高于生菜 ${ }^{[71]}$. 另一方面，同 一植物对不同抗生素的响应也有所不同. Ahmed等 ${ }{ }^{[70]}$ 发现黄瓜、番茄和生菜对磺胺类抗生素(磺胺二 甲嘧啶、磺胺甲恶唑和磺胺二甲氧嘧啶)的累积均高 于四环素类抗生素(土霉素、金霉素)。与四环素类抗 生素相比，磺胺类抗生素的分子量较低，且具有较高 的水溶性，不容易被土壤颗粒吸附，所以容易被植物 组织吸收和累积. 此外, 抗生素对植物不同器官的影 响也不尽相同. Ahmed等人 ${ }^{[70]}$ 提出，抗生素在植物不 同器官内的累积量为根系、叶子高于可食部. 另有研 究表明，恩诺沙星对水芹地下部分生长的影响明显大 于对地上部分的影响 ${ }^{[69]}$. 迟荪琳等人 ${ }^{[72]}$ 通过土培实验 也发现了类似的规律，即生菜和小白菜地下部对四环 素、土霉素、金霉素的富集能力大于地上部。一方面, 抗生素在植物不同器官内的分布差异可能与根部的主 动吸收和表面吸附作用有关 ${ }^{[69]}$; 另一方面也可能是由 于抗生素属于难挥发性化合物，只能通过根系被植物 吸收, 所以对植物的影响作用始于根部 ${ }^{[73]}$. 也有学者 认为, 介质中的抗生素通过被动扩散转移到地下部, 而抗生素从地下部转运到地上部的能力有限, 因而导 致过高浓度的抗生素在地下部累积 ${ }^{[72]}$. 抗生素在植物 体内的不断累积，不仅对植物本身产生毒害作用，也 会随着生物链对人体和其他动物造成危害 ${ }^{[64]}$. 值得注 意的是，抗生素对植物本身产生毒害作用的同时，部
分抗生素也会在植物体内发生降解 ${ }^{[74]}$. 吴小莲 ${ }^{[75]}$ 研究 发现，在不同实验处理下高累积菜心品种对环丙沙星 的代谢能力均显著高于低累积品种, 而且两类菜心品 种的根细胞中环丙沙星的浓度均较低. 这主要是因为 根细胞中的水解酶促进了环丙沙星的降解; 同时根尖 细胞中液泡区室化对环丙沙星去毒也起到非常重要的 作用, 属于“耐性”抗污染胁迫机制.

鉴于抗生素污染对植物和食物链造成的潜在风 险, 可以降解抗生素的植物品种和相应的作用机理研 究格外重要, 但目前的研究工作大多集中在抗生素对 种子萌发、根和茎生长发育的毒理效应以及植物对抗 生素的吸收、累积方面, 对植物降解抗生素的研究还 很少. 抗生素在植物体内的吸收、累积与降解过程比 较复杂, 且因土壤类型、抗生素种类、植物品种和组 织器官的不同而有所差异, 当前关于抗生素在植物体 内的降解机理研究的还不够透彻.

\section{3 抗生素对土壤动物的毒理效应}

作为生态系统的消费者, 土壤动物在促进物质循 环和能量移动方面起到重要的作用. 目前的研究结果 显示，抗生素的残留对土壤动物的生长繁殖造成了不 同程度的影响，而这主要与抗生素的浓度有关(表3). Dong等人 ${ }^{[76]}$ 研究了金霉素和四环素对赤子爱蚯蚓的 毒性效应，结果显示在浓度为 $0.3 \sim 300 \mathrm{mg} / \mathrm{kg}$ 时对赤子 爱蚯蚓的基因毒性具有明显的剂量-效应关系。 Li等 人 $^{[77]}$ 比较了不同浓度的恩诺沙星对蝶蚓的影响, 实验 发现暴露在浓度为 $10 \mathrm{mg} / \mathrm{kg}$ 的恩诺沙星 8 周后, 虾蚓的 活动强度和呼吸作用下降; 当恩诺沙星浓度为 0.1 和 $1.0 \mathrm{mg} / \mathrm{kg}$ 时，蚯蚓则未表现出明显的毒性反应. 另一 项研究结果表明, 浓度为 $30 \mathrm{mg} / \mathrm{kg}$ 的强力霉素对蚯蚓 幼虫也造成了毒害作用 ${ }^{[78]}$. 除了蛏蚓，抗生素对跳虫 和白符䖴的生长和繁殖也造成了影响 ${ }^{[79,80]}$. 例如, 跳虫 暴露于浓度为 $10 \mathrm{mg} / \mathrm{kg}$ 的诺氟沙星和土霉素两周后, 其生长显著被抑制 ${ }^{[79]}$; 在毒理测试中，白符䖴暴露在 浓度为 $1000 \mathrm{mg} / \mathrm{kg}$ 的诺氟沙星环境下，其繁殖数和成 虫体长比对照组分别减少 $34.4 \%$ 和 $9 \%{ }^{[80]}$. 抗生素会引 起土壤动物的氧化应激反应，导致脂质过氧化，进而 促进其产物丙二醛的形成并诱导超氧化物歧化酶、过 氧化物酶、过氧化氢酶的表达, 最终抑制土壤动物的 生长 ${ }^{[80]}$. 也有学者研究发现抗生素对蝶蚓并没有造成 明显的毒性效应. Gao 等人 ${ }^{[81]}$ 对虾蚓进行了回避毒性 
表 3 抗生素对土壤动物的毒理效应

Table 3 Toxicological effects of antibiotics on soil animals

\begin{tabular}{|c|c|c|c|c|}
\hline 抗生素种类 & 抗生素浓度 (mg/kg) & 动物 & 影响效果 & 参考文献 \\
\hline 四环素 & $0.3 \sim 300$ & 蚯蚓 & 致使基因毒性 & {$[76]$} \\
\hline 金霉素 & $0.3 \sim 300$ & & & \\
\hline 强力霉素 & 30 & & 对幼虫造成毒害作用 & {$[78]$} \\
\hline 土霉素 & $0 \sim 2560$ & & $48 \mathrm{~h}$ 内均没有死亡 & {$[81]$} \\
\hline \multirow[t]{2}{*}{ 恩诺沙星 } & $0.1,1.0$ & & 未表现出明显的毒性反应 & {$[77]$} \\
\hline & 10 & & 活动强度和呼吸作用下降 & {$[77]$} \\
\hline 土霉素 & 10 & 跳虫 & 生长显著被抑制 & [79] \\
\hline \multirow[t]{2}{*}{ 诺氟沙星 } & 10 & & & \\
\hline & 1000 & 白符䖴 & 生长繁殖被抑制 & {$[80]$} \\
\hline
\end{tabular}

测试，结果发现蚯蚓暴露于 $0 \sim 2560 \mathrm{mg} / \mathrm{kg}$ 范围的土霉 素后 $48 \mathrm{~h}$ 内均没有死亡. 最近的研究结果也显示, 蚯蚓 对环丙沙星和阿奇霉素并未表现出毒性反应 ${ }^{[12]}$. 由此 看来，目前关于抗生素对土壤动物的影响还尚未达成 统一结论, 而且剂量-效应关系的临界值依然不明确.

\section{4 抗生素对土壤微生物的毒理效应}

抗生素是一类具有杀菌作用的药物, 能直接影响 土壤环境中某些微生物的生长繁殖或改变其群落结 构, 进而打破土壤中的微生态平衡. 例如, Hammesfahr 等人 ${ }^{[82]}$ 向土壤中加入磺胺嘧啶 $4 \mathrm{~d}$ 后, 发现细菌与真菌 的比值从 $70 \%$ 减少到 $57 \%$. 近年来, 随着基因测序技术 的普及, 抗生素对土壤微生物的影响逐渐具体化. Han 等人 ${ }^{[83]}$ 通过元基因组分析得出金霉素和环丙沙星的 添加使得土壤放线菌和菌丝体的相对丰度提高 $0.5 \%$ $236 \%$, 而变形杆菌的丰度降低了 $0.2 \% \sim 27.3 \%$; 优势 菌属(链霉菌、放线菌、分枝杆菌和链球菌)的相对丰 度也显著增加. $\mathrm{Xu}$ 等人 ${ }^{[84]}$ 通过圥余分析发现土壤中放 线菌、扁平菌和疮微菌与磺胺对甲基氧嘧啶、磺胺甲 恶唑和磺胺嘧啶的含量呈正相关，表明抗生素污染可 能引发特异性微生物群落的形成. 还有研究显示, 四 环素增加了土壤中 $\beta$-变形杆菌的丰度, 而梭状芽胞杆 菌和 $\gamma$-变形杆菌的丰度却随着四环素浓度升高而降 低 $^{[85]}$.

在抗生素抑制其标靶微生物的同时，土壤中的其 他微生物可以获得更多的碳源, 呼吸强度也随之改 变 ${ }^{[64]}$. Fang 等人 ${ }^{[86]}$ 发现磺胺嘧啶和金霉素均会抑制土 壤的呼吸作用. 当土壤中的抗生素浓度达到一定水平
后, 可以对土壤微生物的活性产生显著影响. 例如, 有 研究结果显示, 土霉素对菜地和草地土壤中䐂酶的活 性影响表现为“低促高抑”, 对果园和草地土壤的中性 磷酸酶活性均未造成明显影响, 但当其浓度达到 $100 \mathrm{mg} / \mathrm{kg}$ 时对菜地和桑园土壤的中性磷酸酶活性具 有一定的促进作用 ${ }^{[87]}$. Ma等人 ${ }^{[88]}$ 研究结果表明, 添加 浓度为 $100 \mathrm{mg} / \mathrm{kg}$ 的环丙沙星可以激发土壤微生物呼 吸作用, 但同时也抑制了微生物的代谢能力. 最近的研 究结果显示, 金霉素对土壤过氧化氢酶和中性磷酸酶 活性的影响均呈现“抑制-恢复-刺激”的变化趋势; 环 丙沙星可以刺激土壤中性磷酸酶的活性, 但对过氧化 氢酶活性无显著影响 ${ }^{[89]}$.

\section{5 抗生素对土壤中抗性细菌与抗性基因的影响}

过量使用抗生素不仅导致土壤微生物群落结构和 呼吸作用发生改变, 还会使其产生选择性压力, 改变抗 生素抗性细菌 $\left(\mathrm{ARB}_{\mathrm{S}}\right)$ 的丰度和多样性. 一方面, 抗生 素会在动物肠道内诱导抗性菌株的产生, 这些抗性菌 株所含的抗生素抗性基因 $\left(\mathrm{ARG}_{\mathrm{S}}\right)$ 又可以随着畜禽粪 便或有机肥直接排入环境, 并通过水平基因转移使土 著微生物获得抗性 ${ }^{[1,3]}$. 另一方面, 畜昺粪便和有机肥 中残留的抗生素会提供抗生素选择压力, 为抗生素抗 性的产生和水平基因转移提供驱动力, 使土壤中的土 著微生物甚至致病菌获得抗性, 从而给人类健康带来 潜在风险 ${ }^{[2,3]}$.

近年来, 抗生素对土壤微生物的毒理效应已引起 国内外科研工作者的广泛关注. 大量的实验结果表明, 抗生素对土壤中 $\mathrm{ARB}_{\mathrm{S}}$ 的影响主要与抗生素的浓度有 
关. 例如, 有学者对华南地区长期施用粪肥的稻田土壤 进行研究，发现抗性基因的丰度与抗生素浓度显著相 关 ${ }^{[00]}$. 畜禽粪便样品中恩诺沙星、强力霉素、泰乐菌 素和磺胺嘧啶的浓度与 $\mathrm{ARB}_{\mathrm{S}}$ 的耐药率也表现出较明 显的剂量-效应关系 ${ }^{[91]}$. 此外，抗生素的种类差异对土 壤中 $\mathrm{ARB}_{\mathrm{S}}$ 的耐药率也造成了不同的影响. Wang等 人 ${ }^{[92]}$ 发现细菌对泰乐菌素 $(6.4 \% \sim 71.1 \%)$ 的耐药率显著 高于恩诺沙星 $(0.65 \% \sim 15.1 \%)$ ，但随着两者浓度升高， 细菌的耐药率均逐渐下降; 微杆菌(Microbacterium) 和 假单胞菌(Pseudomonas)分别是泰乐菌素和恩诺沙星 最主要的抗性菌，而克雷伯菌(Klebsiella)、沙门氏菌 (Salmonella) 和肠杆菌(Enterobacter) 同时对两者具有 抗性.

$\mathrm{ARB}_{\mathrm{S}}$ 是 $\mathrm{ARG}_{\mathrm{S}}$ 的主要载体，过量使用抗生素改变 了土壤中 $\mathrm{ARB}_{\mathrm{S}}$ 的丰度和多样性, 进而改变 $\mathrm{ARG}_{\mathrm{S}}$ 的丰 度. 例如，诺氟沙星和土霉素的过量使用均使土壤中 跳虫肠道菌的 $\mathrm{ARG}_{\mathrm{S}}$ 丰度和多样性明显增加 ${ }^{[93]}$; 磺胺 甲恶唑的添加则导致土壤中氨基糖苷和万古霉素抗性 基因的丰度显著增加 $(p<0.05)^{[94]}$. 还有研究发现四环

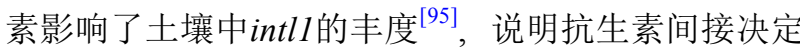
了 $\mathrm{ARG}_{\mathrm{S}}$ 的分布和传播. 抗生素是土壤中 $\mathrm{ARG}_{\mathrm{S}}$ 丰度增 加的根本原因, 所以其浓度和种类能够显著影响 $\mathrm{ARG}_{\mathrm{S}}$ 的分布特征. 研究发现, 抗性基因 erm B, qnrA, erm C和 $q n r S$ 含量与罗红霉素的残留量呈正相关; 大环内酯类 $\mathrm{ARG}_{\mathrm{S}}$ 的丰度则高于氟喹诺酮类 $\mathrm{ARG}_{\mathrm{S}}$ 的丰度 ${ }^{[92]}$. Xu等 ${ }^{[84]}$ 研究结果表明, sull 的丰度与土壤中磺胺嘧啶、 磺胺甲恶唑和磺胺对甲基氧嘧啶的浓度呈正相关；四 环素和磺胺类 $\mathrm{ARG}_{\mathrm{S}}$ 丰度远高于其他抗生素. Wang等

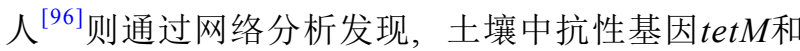
tet $Q$ 的丰度分别与强力霉素和土霉素呈正相关; 而 ermB 和blaCTX-M 的丰度则分别与罗红霉素和头孢氨 茮相关.

值得注意的是，当含有抗性基因的微生物死亡后， 体内的遗传物质可与环境中的腐殖质、矿物质等结 合, 因此很难被核酸酶分解, 最终导致其在环境中持续 传播扩散 ${ }^{[97]} . \mathrm{ARG}_{\mathrm{S}}$ 可通过垂直和水平转移进行扩散, 这不仅改变土壤生态系统的微生物群落组成和多样 性, 还会通过食物链或其他方式传播给人类, 进而危害 公众健康. 虽然关于抗生素对土壤微生物的毒理效应 已开展了大量的研究工作，但由于抗生素种类众多和 土壤环境的复杂性，关于抗生素的不同类型及其浓度
水平和复合污染对环境中 $\mathrm{ARB}_{\mathrm{S}}$ 和 $\mathrm{ARG}_{\mathrm{S}}$ 丰度的影响及 其作用机理的探究仍然非常初步.

\section{4 抗生素的危害调控}

兽用抗生素随着畜禽粪便进入到土壤环境中, 对 植物、土壤动物和微生物均造成一定的毒理效应，以 及改变抗性细菌和抗性基因的多样性和丰度，进而通 过食物链对人类健康造成威胁. 因此，采取有效的调 控措施来降低土壤中抗生素的浓度是十分必要的. 目 前, 去除土壤中抗生素的方法可分为抗生素排放环节的 直接处理和进入土壤环境后的污染控制. 其中, 在排放 环节的直接处理的方法主要包括好氧堆肥化、厌氧消 化和畜禽粪便炭化; 进入土壤环境后的污染控制方法 主要包括生物炭和石墨烯基复合材料的吸附作用.

\section{1 抗生素排放环节的直接处理}

\subsection{1 好氧堆肥化}

好氧堆肥化是目前使畜禽粪便无害化和资源化的 主要途径，粪便中的抗生素在这一过程中会通过生物 和非生物作用全部或部分降解(图 $\left.{ }^{[98]}\right)$, 进而降低抗生 素的潜在危害. 好氧堆肥化处理技术主要包括普通高 温堆肥化和超高温堆肥化 ${ }^{[99]}$, 其中高温堆肥化是处理 畜禽粪便最简单、经济、适用的方法，也是养殖场粪 肥施用至农田前最为普遍的处理方法 ${ }^{[100]}$.

在好氧堆肥过程中抗生素可以发生微生物降解和 热降解. 研究表明, 在堆肥过程中, 部分抗生素可以被 堆体中的好氧微生物吸附或降解, 且真菌和细菌均有 可能参与降解过程 ${ }^{[30]}$. 时红蕾等人 ${ }^{[101]}$ 却发现堆肥中 微生物对环丙沙星降解的贡献率仅占约 $20 \%$ ，这说明 随着堆体温度的迅速升高，除了微生物降解，抗生素 还可能发生分解转变成别的化合物. 因为堆肥期间堆 体温度通常达不到抗生素热裂解的温度，所以水解是 其主要的分解方式 ${ }^{[102]}$. 在堆肥降解过程中, 温度是影 响畜禽粪便中抗生素去除的重要条件. 孟䂞等人 ${ }^{[103]}$ 对 鸡粪进行高温堆肥来探究氟喹诺酮类抗生素的去除效 果, 发现抗生素的去除率随着温度的升高而增加. 另一 项研究也表明，四环素、金霉素、磺胺嘧啶和环丙沙 星在高温堆肥中的去除效果好于低温，且去除率都在 $90 \%$ 以上 ${ }^{[101]}$. 由于自身化学性质的差别, 不同抗生素 之间对温度变化的敏感性存在差异. Feng等人 ${ }^{[104]}$ 研究 


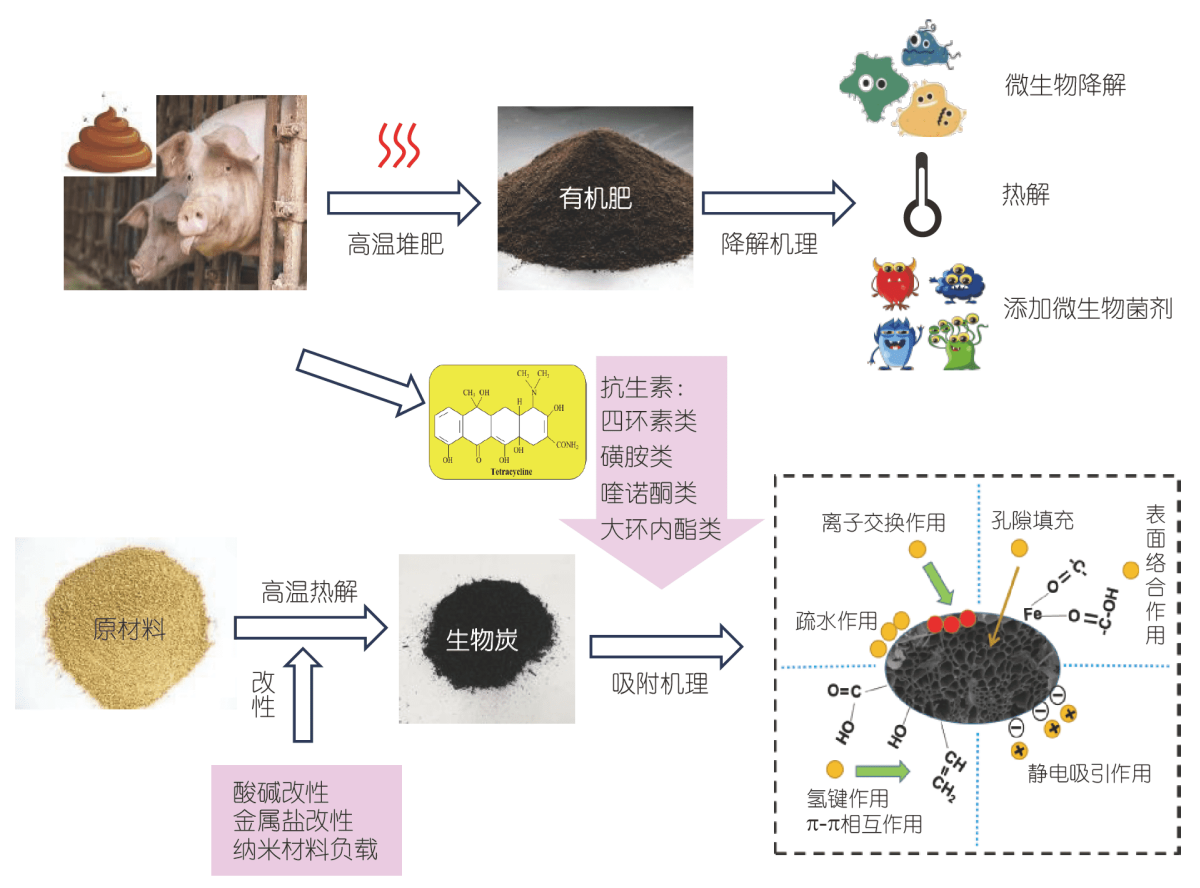

图 4 (网络版彩图)采用堆肥和生物炭吸附调控抗生素危害的示意图 ${ }^{[98]}$

Figure 4 (Color online) Schematic illustration on mitigating the risk of antibiotics by composting and biochar adsorption [98].

发现, 在复合污染条件下, 红霉素受温度变化的影响远 大于其他类型抗生素, 而且红霉素的半衰期在低温时 为 $142 \mathrm{~d}$, 而在高温条件下仅为 $3 \mathrm{~d}$.

大量的研究表明好氧堆肥对畜禽粪便中抗生素的 降解效果与抗生素的类型、浓度和堆肥条件(含水 率、通气状态等)密切相关. 例如, 四环素类抗生素比 磺酰胺类和喹诺酮类抗生素更容易在堆肥过程中被降 解 ${ }^{[00]}$. 喹诺酮类和磺酰胺类属于人工合成药物, 而四 环素类属于天然抗生素, 因此更容易被微生物分解. 另有研究表明, 抗生素对部分微生物生长的抑制作用 会推迟腐熟时间，进而影响堆肥化效果，所以粪便中 抗生素的浓度越高, 对初始微生物菌群的影响越大, 去除率更低 ${ }^{[105]}$. Yang等人 ${ }^{[106]}$ 也证实了初始浓度增加3 倍后，恩诺沙星、诺氟沙星、沙氟沙星和洛美沙星的 降解率均有所降低. 堆体中的含水量也是促进抗生素 降解的重要影响因素. 已经有研究发现水分促进了磺 胺二甲嘧啶、金霉素和泰乐菌素的降解 ${ }^{[107]}$. 但 Guo 等 人 ${ }^{[108]}$ 认为对于好氧堆肥，含水量应控制在 $50 \% \sim 60 \%$; 若超过 $60 \%$, 水分会将堆体中的孔隙堵住, 致使氧气流 通不畅, 从而抑制好氧微生物的代谢能力. 此外, 堆肥 时的通气状态也会直接影响微生物对抗生素的分解速
度，同时在降温和腐熟期阶段还有利于堆体散热和干 燥. 例如, Munaretto等人 ${ }^{[109]}$ 实验结果表明，在强制通 风、强制翻创通风处理条件下莫能菌素的去除率分别 为 $35.6 \% ， 39.9 \%$, 高于翻刨通风(15.9\%)和自然堆放 $(19.8 \%)$ 条件下的去除率. Yuan等人 ${ }^{[110]}$ 比较了堆体中 不同含氧量对抗生素降解的影响, 结果显示含氧量控 制在 $10 \%$ 20\%时可促进抗生素的降解. 若通气量过低 会形成局部厌氧环境, 使好氧微生物的活性降低; 而通 气过量则使好氧菌繁殖速度加快, 导致有机质被大量 降解、氮素损失、腐殖质化系数降低, 进而影响堆肥 腐熟速率。

微生物在好氧堆肥化降解抗生素过程中起到重要 的作用, 所以添加微生物菌剂是促进抗生素降解的重 要途径. 肖礼等人 ${ }^{[111]}$ 研究表明添加微生物菌剂(白腐 真菌、氨化和硝化菌剂)可加速猪粪中四环素类抗生 素的降解. 这主要是因为白腐真菌产生的天然木质素 过氧化物酶和锰过氧化物酶在体外对四环素有很强的 降解能力 ${ }^{[112]}$. 另有研究显示, 在鸡粪堆肥中添加 $0.3 \%$ 枯草芽孢杆菌和地衣芽孢杆菌复合菌剂对四环素的降 解基本无影响, 却显著促进了土霉素的降解 ${ }^{[113]}$. 另外, 孟否等人 ${ }^{[103]}$ 还发现外源添加白腐真菌可以显著提高 
堆肥过程中氟喹诺酮类抗生素的降解率，尤其对诺氟 沙星的去除效果显著．整体上看，添加微生物菌剂可 促进堆肥过程中抗生素的降解，但降解效果也因抗生 素种类不同而存在差异.

综上所述，大量的研究已经表明堆肥能够降低畜 禽粪便中的抗生素残留浓度，但抗生素在此过程中的 降解受到多种因素的影响，如抗生素类型、残留浓 度、堆肥条件及堆肥基质等. 因此，在无法改变抗生 素种类和浓度的前提下，如何改进堆肥条件以促进抗 生素的降解可能是以后研究工作的重要切入点. 此外, 堆肥过程中添加具有强降解能力的微生物菌剂，可提 高抗生素降解效果并减少耐药基因的传播，但重点和 难点在于如何篮选出具有降解特定抗生素功能的菌 株、复合菌种的组合以及适宜条件的控制. 因此, 在以 上方面, 仍然需要更深入的系统研究.

\subsection{2 厌氧消化}

厌氧消化也是去除畜禽粪便中抗生素的方法之 一. 抗生素在厌氧消化中的降解率主要与其种类有关. 例如，Mohring等人 ${ }^{[114]}$ 研究了七种磺酰胺和甲氧芐氨 嘧啶在猪粪厌氧消化过程中的降解行为. 结果显示, 五周内磺胺甲基嘧啶、磺胺嘧啶、磺胺地索辛、磺胺 甲恶唑和甲氧芐氨嘧啶几乎完全被降解，而磺胺二甲 嘧啶、磺胺噻唑和磺胺甲氧嗪仍有 $40 \%$ $60 \%$ 的残留, 这可能是因为它们结构的不同导致了颗粒相分布和微 生物降解难度的差异. Álvarez等人 ${ }^{[115]}$ 研究了猪粪厌氧 消化过程中不同浓度 $(10,50,100 \mathrm{mg} / \mathrm{L})$ 的土霉素和金 霉素的降解情况，结果表明，金霉素(91\% 92.5\%)的降 解率远高于土霉素(43\% 69.5\%). 土霉素容易与畜禽 粪便中的二价阳离子、腐殖酸、蛋白质和有机物等结 合, 导致其难以被降解 ${ }^{[116]}$. 此外, 厌氧消化过程中抗生 素的去除率还受到温度 ${ }^{[117]}$ 、污泥性质、混合速率 ${ }^{[118]}$ 和反应时间 ${ }^{[119]}$ 等方面的影响.

目前大多数的研究结果表明了厌氧消化过程能够 有效地去除畜禽粪便中的抗生素，但其产物仍可能存 在不同浓度的抗生素残留 ${ }^{[114,116]}$ ，若利用沼渣制作有 机肥还田后还可能造成潜在的生物毒性. 另外, Nurk 等人 ${ }^{[120]}$ 提出吸附作用也是厌氧消化过程中抗生素的 去除途径之一，而实验结果也证明抗生素可以再次从 厌氧消化污泥中解吸, 所以厌氧消化可能并不是减少 抗生素向环境中释放的有效途径. 由此可见，通过厌
氧消化去除抗生素的效果还存在一些争议.

\subsection{3 畜禽粪便炭化}

近年来，考虑到传统的好氧堆肥化和厌氧消化处 理导致的抗生素残留问题，通过高温热解将畜禽粪便 制成生物炭从而去除抗生素的方法引起了越来越多的 研究兴趣. 崔亚男等人 ${ }^{[121]}$ 对比分析了等量猪粪、猪粪 堆肥化、猪粪生物炭3种处理的抗生素残留浓度. 结果 显示, 与新鲜猪粪、猪粪堆肥化对比, 炭化处理几乎 $100 \%$ 去除了土霉素. 另有研究结果表明, 在将猪粪转 化为生物炭的过程中，90种抗生素抗性基因被完全分 解 ${ }^{[122]}$. 在炭化处理过程中, 影响抗生素去除效果的因 素主要是热解温度. $\mathrm{Li}$ 等人 ${ }^{[123]}$ 将污泥和猪粪在 $600^{\circ} \mathrm{C}$ 下进行共热解，结果显示，原料中的泰乐菌素、四环 素、金霉素、强力霉素、磺胺嘧啶和磺胺甲恶唑均被 完全分解. Tian等人 ${ }^{[124]}$ 在 $300^{\circ} \mathrm{C} \sim 700^{\circ} \mathrm{C}$ 条件下分别将 猪粪和鸡粪制成生物炭, 研究了抗生素的去除效果. 结果表明，整体上泰乐菌素、四环素、金霉素、强力 霉素、磺胺二甲嘧啶、磺胺嘧啶和磺胺甲恶唑的去除 效果令人满意, 且 $600^{\circ} \mathrm{C}$ 是完全去除这些抗生素的最 低热解温度. 随着热解温度升高, 抗生素中的脂肪族 $\mathrm{C}-\mathrm{H}$ 会转化成 $\mathrm{CO}_{2}$ 和 $\mathrm{CH}_{4}$ 等气体, 同时发生脱氢反应生 成C-O-C基团, 进而转化为芳香族等碳链结构, 最终令 抗生素分解 ${ }^{[124]}$.

目前的研究结果表明，与好氧堆肥化、厌氧消化 处理方法相比, 热解炭化处理技术在彻底清除抗生素 方面具有许多优势 ${ }^{[121,124,125]}$. 该方法既能安全、高效 地去除抗生素，又可将生物炭用作吸附剂和土壤改良 剂 ${ }^{[123,126]}$. 值得注意的是, 畜禽粪便通常含水率高, 将 其制备成生物炭的成本高. 与此同时, 畜舍粪便成分复 杂, 除抗生素外还含有较高含量的铜、锌等重金属, 会 被浓缩到生物炭上, 因此, 对畜禽粪便生物炭施用于农 田土壤的风险评估还需要加强研究.

\section{2 进入土壤环境后的污染控制}

\subsection{1 (改性)生物炭对抗生素的吸附}

生物炭是在缺氧条件下，由农作物秸秆、动物粪 便、木材和城市污泥等有机废弃物高温热解而制成的 细粒、富碳多孔物质. 因其具有较高的比表面积和纳 米孔隙率，且表面具有芳香性和功能性，生物炭可以 作为一种低成本的环保吸附剂。与土壤有机质相比, 
生物炭对抗生素有较强的吸附能力 ${ }^{[127]}$, 对抗生素的吸 附、解吸、降解、浸出和生物可利用性等产生显著影 响. 如图4所示, 生物炭可通过氢键、表面络合、静电 吸附、离子交换等作用对土壤中抗生素的吸附/解 吸、降解等过程产生显著影响. 研究表明, 生物炭可明 显促进土壤中泰乐菌素的吸附, 同时对其解吸具有延 滞作用 ${ }^{[128]}$. 张涵瑜等人 ${ }^{[129]}$ 发现通过热解芦苇秸秆和 城市污泥制备的两种生物炭对诺氟沙星的吸附率分别 达 $70 \%$ 和 $60 \%$ 以上, 这是因为生物炭上的含氧官能团 为诺氟沙星分子提供了吸附位点, 促进了两者之间氢 键的形成. Wang 等人 ${ }^{[130]}$ 也证实了在猪粪堆肥过程中 添加生物炭有利于环丙沙星、四环素和诺氟沙星的去 除, 添加 $9 \%(w / w)$ 的生物炭可使残留的环丙沙星浓度 降低 $98.9 \%$.

大量的研究表明, 生物炭对抗生素的吸附受到生 物炭自身性质的影响. 韩旸等人 ${ }^{[127]}$ 发现胶体粒径的生 物炭对磺胺甲恶唑的吸附能力显著强于粗粒径的生物 炭, 这是因为前者的比表面积更大、孔隙结构更多. 研 究表明, 与原材料相比, 热解温度的高低对生物炭的结 构、性质和吸附稳定性的影响更大 ${ }^{[131,132]}$. 与低温生物 炭相比, 高温制备的生物炭具有较高的比表面积、较 大的微孔和中孔容积, 因而对抗生素的吸附能力更 强 ${ }^{[131,132]}$. 此外, 土壤环境也是影响生物炭对抗生素吸 附效果的重要因素. 与抗生素在土壤上吸附类似, 生物 炭对抗生素的吸附作用也受到 $\mathrm{pH}$ 的显著影响, 如在弱 酸性条件下生物炭对磺酰胺类和四环素类抗生素的吸 附最强 ${ }^{[133,134]}$. 土壤中广泛存在有机质, 其中腐殖酸可 以直接与生物炭的极性部分通过氢键或者与疏水部分 通过 $\pi-\pi$ 电子给体-受体产生交互作用，从而间接影响 生物炭对抗生素的吸附. Lian等人 ${ }^{[135]}$ 研究表明腐殖酸 可以抑制生物炭对磺酰胺类抗生素的吸附, 并且与抗 生素的疏水性、极性、电离性质以及腐殖酸的浓度密 切相关. Yang等人 ${ }^{[136]}$ 也发现鸡粪肥溶出的有机质对生 物炭吸附环丙沙星有促进作用.

传统高温热解法所制备的生物炭受自身条件所 限, 对污染物的吸附去除并没有达到十分理想的效果. 国内外学者建立了多种物理、化学和生物改性方法以 提高生物炭对污染物的吸附性能. 其中, 物理改性法主 要通过进一步的高温热解改变生物炭的孔隙结构、增 大其比表面积以增强吸附性能, 生物改性法则利用附 着在生物炭表面的微生物来增强其吸附效果, 而化学
改性法则主要利用化学手段处理生物炭来改变表面官 能团和比表面积, 达到提高吸附性能的目的. 根据现有 研究结果来看, 目前生物炭改性最常用的是化学改性 法, 主要包括金属盐改性、纳米材料负载和酸碱改性. 在酸改性方面, Sun等人 ${ }^{[137]}$ 研究发现, 经过低分子量有 机酸(柠檬酸和苹果酸)处理后的生物炭对磺胺甲恶唑 的吸附作用增加, 这可以归因于微孔率提高以及通过 破坏溶解有机物和金属阳离子与生物炭的表面连接而 暴露出更多的吸附位点. 其他学者的实验结果也证明 了酸改性可有效增加生物炭表面含氧官能团的数量, 为抗生素分子的吸附提供更多的位点, 从而提高其对 四环素和磺胺噻唑的吸附能力 ${ }^{[138,139]}$. 与酸改性不同, 金属盐改性的作用机制是使金属氧化物或氢氧化物负 载在生物炭表面, 从而提高其对阴离子型有机污染物 的吸附能力. 如生物炭经过 $\mathrm{FeCl}_{3}$ 改性后可增强对四环 素的吸附能力, 主要机制是表面 $\mathrm{Fe}^{3+}$ 与四环素的络合 作用 ${ }^{[140]}$. 另一项研究显示, 生物炭经高锰酸钾改性后 比表面积、总孔体积和羰基基团均显著增加, 从而能 够有效地去除磺胺嘧啶和泰乐菌素 ${ }^{[141]}$. 随着近年来对 纳米材料的研究, 纳米材料负载生物炭这种方法已引 起了研究者的关注. Guo等人 ${ }^{[142]}$ 研究发现负载针铁矿 后生物炭表面的针铁矿纳米颗粒能提供更多的活性吸 附位点, 使其对泰乐菌素的吸附能力明显增强. Yang等 人 ${ }^{[136]}$ 使用新型二维纳米材料 $\mathrm{MoS}_{2}$ 处理生物炭, 实验 结果显示 $\mathrm{MoS}_{2}$ 负载生物炭具有合适的孔隙结构且比 表面积极大地增加, 使环丙沙星更容易与活性位点接 触, 因而显著提高了对环丙沙星的吸附性能.

综上所述, 生物炭对抗生素具有优良的吸附固定 作用, 同时其吸附效果受自身性质和环境影响很大. 改性生物炭相比原生物炭能够更好地吸附抗生素, 但 针对长期添加改性生物炭对土壤中抗生素的吸附稳定 性的研究还鲜有报道. 目前关于(改性)生物炭对抗生 素的吸附研究多数以单一抗生素为研究对象, 而实际 土壤中一般都是多种抗生素共存的, 这势必造成竞争 吸附, 进而对吸附效果造成较大影响. 另外, 考虑到 (改性)生物炭本身可能携带的内源性污染物(如多环芳 烃、重金属等)和纳米颗粒的释放与迁移能力, 在将来 的研究中还需进一步结合实际的施用环境、抗生素类 型和生物炭毒性等各方面的因素, 来系统评估(改性) 生物炭吸附去除土壤中抗生素的长期效果、影响因素 及环境风险等. 


\subsection{2 石墨烯基复合材料对抗生素的吸附}

除(改性)生物炭材料外，以石墨烯为代表的碳纳 米材料也因其高比表面积和丰富的微孔、介孔结构和 优良的吸附性能引起了学者们的广泛关注. 研究表明, 石墨烯、氧化石墨烯 $(\mathrm{GO})$ 和还原氧化石墨烯均具有 较高的吸附性能，对四环素和磺胺甲恶唑具有很好的 吸附效果 ${ }^{[143,144]}$. 随着对石墨烯研究的深入, 越来越多 的学者在GO的基础上进一步研究石墨烯基复合材料, 以期达到更好的吸附效果. 研究种类主要包括磁性石 墨烯、聚合物/石墨烯、三维石墨烯凝胶和石墨烯/生 物炭等. 石墨烯基复合材料主要通过 $\pi-\pi$ 堆叠、 $\pi-\pi$ 电 子供体-受体相互作用、静电吸附、氢键作用、阳离 子- $\pi$ 键作用以及其他特定的机理作用(如孔隙填充、 络合作用、阳离子交换等)促进对抗生素的吸附 ${ }^{[145]}$. 研究表明, 经过二氧化硫腿还原的磁性 GO和纳米纤维 素/GO气凝胶对四环素的吸附容量分别为 $1233^{[146]}$ 和 $454.6 \mathrm{mg} / \mathrm{g}^{[147]}$ ，明显高于 $\mathrm{GO}$ 对四环素的吸附容量 $(313 \mathrm{mg} / \mathrm{g})^{[144]}$. 与此同时, 吸附效果因复合材料和抗 生素种类的不同而具有显著的差异，例如，二氧化硫 脲还原的磁性GO对四环素的吸附效果高于纳米纤维 素/ $\mathrm{GO}$ 气凝胶 ${ }^{[146,147]}$. $\mathrm{YaO}$ 等人 ${ }^{[147]}$ 则发现纳米纤维素/ $\mathrm{GO}$ 气凝胶对六类抗生素的吸附顺序为：四环素 $>$ 喹 诺酮 $>$ 磺酰胺 $>$ 氯霉素 $>\beta$-内酰胺 $>$ 大环内酯. 另外, Huang等人 ${ }^{[148]}$ 将 $\mathrm{GO}$ 和竹屑生物炭结合制成了 $\mathrm{GO} /$ 生 物炭纳米复合材料, 发现其对磺胺二甲嘧啶的吸附效 果增加了1.14倍.

与石墨烯纳米粉体相比，石墨烯基复合材料具有 更高的比表面积和更优异的吸附性能，但其解吸性能 还不太清楚. 目前该类复合材料的吸附性能主要针对 单一抗生素开展，且因负载材料和抗生素种类不同而 存在差异. 因此，如何制备出对土壤中多种抗生素均 具有良好吸附效果的复合材料还需要更多的探索. 此 外，在使用新型纳米材料处理生物炭或制备石墨烯基 复合材料时，应加强对这类材料生态风险的评估工作， 避免对土壤环境造成二次污染，这对改性生物炭和石 墨烯基复合材料在土壤抗生素污染危害控制中的推广 应用具有重要的现实意义.

\section{5 总结与展望}

抗生素在养殖行业防治动物疾病和促生长方面发
挥了巨大的作用，但也带来了环境污染和公共健康方 面的问题与挑战. 研究能够降低甚至去除土壤中抗生 素残留的方法，是保护土壤安全和人体健康的重要途 径之一, 而深入了解抗生素的环境行为和毒理效应则 是有针对性地建立污控措施的必要前提. 本文对兽用 抗生素在土壤环境中的吸附/解吸和降解行为, 对植 物、土壤动物和微生物的毒性效应，及其危害调控方 法进行了综述, 将近年来国内外的主要研究成果进行 了系统性总结. 目前仍然存在一些基础性问题尚未完 全解释清楚, 需要研究者继续深入探索, 具体如下.

(1) 目前有关土壤中抗生素降解的研究仍处于对 相关机理的认识和探索阶段. 土壤环境条件复杂，抗 生素类型多样，可结合抗生素的种类、具体的土壤质 地以及气候因素来开展试验, 以此促进对抗生素在土 壤中的吸附与降解机理的深入了解. 另外, 部分抗生 素的降解产物仍可能具有生物毒性，但是近年来在抗 生素降解产物的迁移和去除方面并未进行更深入的研 究. 抗生素降解产物的环境行为和可能造成的二次毒 性效应，也可为土壤中抗生素的作用机理研究提供新 的思考角度

(2) 抗生素对土壤动物和植物生理指标间的剂量效应关系主要表现为“低促高抑”，但临界值并不明确. 因此, 还需要开展更多的研究工作. 一方面, 在培养实 验中, 扩大受试对象的范围, 将抗生素分类并细化浓度 梯度, 并根据不同生理指标探索影响临界值存在差异 的根本原因. 另一方面, 利用现代分子生物学技术, 在 分子水平深入探究抗生素在植物和土壤动物体内的累 积和降解机理. 两者的发展与结合可以对受污染土壤 的作物种植和含抗生素畜禽粪便的施用量提供可靠的 参考依据.

(3) 实际土壤中一般都是多种抗生素共存的, 而现 有研究大多以单一抗生素为考察对象, 这并不能充分 反映抗生素对微生物群落结构和抗性基因的影响. 因 此，探讨不同类型抗生素复合污染和不同浓度水平对 微生物呼吸作用和多样性以及酶活性的作用机制, 进 一步量化抗生素污染对 $\mathrm{ARG}_{\mathrm{S}}$ 丰度的贡献，应该是未 来几年抗生素毒性效应研究方面的重点.

（4）好氧堆肥是目前使畜禽粪便无害化和资源化 的主要途径, 但此过程受到多种因素的影响. 为了促 进堆肥过程中抗生素的降解效果，可通过优化底物、 调整通气量或通气方式、控制堆肥时间和含水量等方 
法有针对性地优化堆肥条件. 添加微生物菌剂也可提 高堆肥对畜禽粪便中抗生素的去除效果并减少抗性基 因的传播，但难点在于具有强降解能力菌株的篮选和 不同菌种的组合，并通过酶工程等技术手段将抗生素 降解酶提取出来.

（5）基于改性生物炭和石墨烯基复合材料的抗生 素污染控制方法还有很大的发展空间. 可通过结合抗
生素种类和土壤环境来进一步优化改良方法, 研究能 够在土壤中长期、高效、稳定地吸附多种抗生素的改 性生物炭和石墨烯基复合材料. 另外, 考虑到其可能携 带的内源性污染物和纳米颗粒物的迁移释放, 还应加 强关于改性生物炭和石墨烯基复合材料施用于土壤后 对抗生素的去除效果和生态风险的研究, 这对将来农 田土壤中抗生素污染的调控具有重要的参考价值.

\section{参考文献}

$1 \mathrm{Hu}$ Y, Cheng H. Research opportunities for antimicrobial resistance control in China's factory farming. Environ Sci Technol, 2014, 48: 53645365

$2 \mathrm{Hu} \mathrm{Y}$, Cheng $\mathrm{H}$. Use of veterinary antimicrobials in China and efforts to improve their rational use. J glob Antimicrobial Resistance, 2015, 3: 144-146

$3 \mathrm{Hu} \mathrm{Y}$, Cheng H. Health risk from veterinary antimicrobial use in China's food animal production and its reduction. Environ Pollution, 2016, 219: 993-997

$4 \mathrm{Hu} \mathrm{Y}$, Cheng $\mathrm{H}$. Elevated antimicrobial residues in animal food products call for institutional changes on veterinary drug management and animal food product surveillance in China. Int J Antimicrobial Agents, 2018, 51: 165-166

$5 \mathrm{Hu}$ X G, Luo Y, Zhou Q X, et al. Determination of thirteen antibiotics residuesin manureby solid phase extractionand high performance liquid chromatography (in Chinese). J Anal Chem, 2008, 36: 1162-1166 [胡献刚, 罗义, 周启星, 等. 固相萃取-高效液相色谱法测定畜牧粪便中13 种抗生素药物残留. 分析化学, 2008, 36: 1162-1166]

6 Tai Y P, Luo X D, Mo C H. et al. Occurrence of quinolone and sulfonamide antibiotics in swine and cattle manures from large-scale feeding operations of Guangdong Province (in Chinese). Environ Sci, 2011, 32: 1188-1193 [邰义萍, 罗晓栋, 莫测辉, 等. 广东省畜牧粪便中喹诺酮类 和磺胺类抗生素的含量与分布特征研究. 环境科学, 2011, 32: 1188-1193]

7 Zhang H M, Zhang M K, Gu G P. Residues of tetracyclines in livestock and poultry manures and agricultural soils from north Zhejiang Province (in Chinese). J Ecol Rural Environ, 2008, 24: 69-73 [张慧敏, 章明奎, 顾国平. 浙北地区畜昺粪便和农田土壤中四环素类抗生素残留. 生态 与农村环境学报, 2008, 24: 69-73]

8 Wang J, Han J Z. Effects of heavy metals and antibiotics on soil and vegetables (in Chinese). J Ecol Rural Environ, 2008, 24: 90-93 [王瑾, 韩剑 众. 饲料中重金属和抗生素对土壤和蔬菜的影响. 生态与农村环境学报, 2008, 24: 90-93]

9 Chen H Y, Fan T, Ye W L, et al. Investigation of three sulfonamides in soils from vegetable lands of Anhui Province (in Chinese). J Anhui Agr Univ, 2014, 41: 474-478 [陈海燕, 㚞霆, 叶文玲, 等. 安徽省菜地土壤中 3 种磺胺类抗生素的残留调查. 安徽农业大学学报, 2014, 41: 474478]

10 Ge F, Guo K, Tan L C, et al. Simultaneous determination of residues of four typical categories of veterinary antibiotics in organic fertilizers (in Chinese). J Ecol Rural Environ, 2012, 28: 587-594 [葛峰, 郭坤, 谭丽超, 等. 有机肥中4类典型兽药抗生素的多残留测定. 生态与农村环境 学报, 2012, 28: 587-594]

11 Tang C L, Zhang W Q, Xia W, et al. Determination of tetracycline antibiotic residues in organic manure by SPE-HPLC (in Chinese). Soil Fert Sci China, 2011, 2: 92-95 [唐春玲, 张文清, 夏玮, 等. 固相萃取-高效液相色谱法测定有机肥中四环素类抗生素药物残留. 中国土壤与肥 料, 2011, 2: 92-95]

12 Sidhu H, O'Connor G, Ogram A, et al. Bioavailability of biosolids-borne ciprofloxacin and azithromycin to terrestrial organisms: Microbial toxicity and earthworm responses. Sci Total Environ, 2019, 650: 18-26

13 Wu Q, Que Z, Li Z, et al. Photodegradation of ciprofloxacin adsorbed in the intracrystalline space of montmorillonite. J Hazard Mater, 2018, 359: 414-420

14 Martínez-Hernández V, Meffe R, Herrera López S, et al. The role of sorption and biodegradation in the removal of acetaminophen, carbamazepine, caffeine, naproxen and sulfamethoxazole during soil contact: A kinetics study. Sci Total Environ, 2016, 559: 232-241

15 Wang S, Wang H. Adsorption behavior of antibiotic in soil environment: A critical review. Front Environ Sci Eng, 2015, 9: 565-574 
16 Huang C H, Renew J E, Smeby K L, et al. Assessment of potential antibiotic contaminants in water and preliminary occurrence analysis. J Contemp Water Res Educ, 2011, 120: 30-40

17 Cycoń M, Mrozik A, Piotrowska-Seget Z. Antibiotics in the soil environment-Degradation and their impact on microbial activity and diversity. Front Microbiol, 2019, 10: 338

18 Mesa L M, Hörler J, Lindt I, et al. Effects of the antiparasitic drug moxidectin in cattle dung on zooplankton and benthic invertebrates and its accumulation in a water-Sediment system. Arch Environ Contam Toxicol, 2018, 75: 316-326

19 Riaz L, Mahmood T, Khalid A, et al. Fluoroquinolones (FQs) in the environment: A review on their abundance, sorption and toxicity in soil. Chemosphere, 2018, 191: 704-720

20 Bílková Z, Malá J, Hrich K. Fate and behaviour of veterinary sulphonamides under denitrifying conditions. Sci Total Environ, 2019, 695: 133824

21 Fernández-Calviño D, Bermúdez-Couso A, Arias-Estévez M, et al. Competitive adsorption/desorption of tetracycline, oxytetracycline and chlortetracycline on two acid soils: Stirred flow chamber experiments. Chemosphere, 2015, 134: 361-366

22 Riaz L, Mahmood T, Yang Q, et al. Sorption and desorption behavior of fluoroquinolone antibiotics in an agricultural soil. Pedosphere, 2019, 29: 676-680

23 Park J Y, Huwe B. Effect of $\mathrm{pH}$ and soil structure on transport of sulfonamide antibiotics in agricultural soils. Environ Pollution, 2016, 213: $561-570$

24 Liu Z, Han Y, Jing M, et al. Sorption and transport of sulfonamides in soils amended with wheat straw-derived biochar: Effects of water pH, coexistence copper ion, and dissolved organic matter. J Soils Sediments, 2017, 17: 771-779

25 Kulshrestha P, Giese, R F, Aga D S. Investigating the molecular interactions of oxytetracycline in clay and organic matter: Insights on factors affecting its mobility in soil. Environ Sci Technol, 2004, 38: 4097-4105

26 Zhang D, Yang S, Wang Y, et al. Adsorption characteristics of oxytetracycline by different fractions of organic matter in sedimentary soil. Environ Sci Pollut Res, 2019, 26: 5668-5679

27 Goulas A, Bourdat-Deschamps M, Nélieu S, et al. Development of a soft extraction method for sulfamethoxazole and transformation products from agricultural soils: Effects of organic matter co-extraction on the environmental availability assessment. Sci Total Environ, 2017, 607-608: $1037-1048$

28 Leng Y, Bao J, Chang G, et al. Biotransformation of tetracycline by a novel bacterial strain Stenotrophomonas maltophilia DT1. J Hazard Mater, 2016, 318: 125-133

29 Shao S, Hu Y, Cheng J, et al. Biodegradation mechanism of tetracycline (TEC) by strain klebsiella sp. SQY5 as revealed through products analysis and genomics. Ecotoxicol Environ Saf, 2019, 185: 109676

30 Liu Y W, Li Z J, Feng Y, et al. Research progress in microbial degradation of antibiotics (in Chinese). J Agro-Environ Sci, 2016, 35: 212-224 [刘元望, 李兆君, 冯瑶, 等. 微生物降解抗生素的研究进展. 农业环境科学学报, 2016, 35: 212-224]

31 Wen X, Jia Y, Li J. Degradation of tetracycline and oxytetracycline by crude lignin peroxidase prepared from Phanerochaete chrysosporium -A white rot fungus. Chemosphere, 2009, 75: 1003-1007

32 Prieto A, Möder M, Rodil R, et al. Degradation of the antibiotics norfloxacin and ciprofloxacin by a white-rot fungus and identification of degradation products. Bioresource Tech, 2011, 102: 10987-10995

33 Hirth N, Topp E, Dörfler U, et al. An effective bioremediation approach for enhanced microbial degradation of the veterinary antibiotic sulfamethazine in an agricultural soil. Chem Biol Technol Agric, 2016, 3: 29

34 Mulla S I, Hu A, Sun Q, et al. Biodegradation of sulfamethoxazole in bacteria from three different origins. J Environ Manage, 2018, 206: 93102

35 Wen X, Wang Y, Zou Y, et al. No evidential correlation between veterinary antibiotic degradation ability and resistance genes in microorganisms during the biodegradation of doxycycline. Ecotoxicol Environ Saf, 2018, 147: 759-766

36 Conn K E, Siegrist R L, Barber L B, et al. Fate of trace organic compounds during vadose zone soil treatment in an onsite wastewater system. Environ Toxicol Chem, 2010, 29: 285-293

37 Liu W, Wang H, Chen X J, et al. Progress on degradation of antibiotics in environment (in Chinese). Prog Vet Med, 2009, 30: 89-94 [刘伟, 王 慧, 陈小军, 等. 抗生素在环境中降解的研究进展. 动物医学进展, 2009, 30: 89-94]

38 Yu S, Wang M, Hong Y W. Antibiotics in environmental matrices and their effects on microbial ecosystems (in Chinese). Acta Ecol Sin, 2011, 
31: 4437-4446 [俞慎, 王敏, 洪有为. 环境介质中的抗生素及其微生物生态效应. 生态学报, 2011, 31: 4437-4446]

39 Shen G, Zhang Y, Hu S, et al. Adsorption and degradation of sulfadiazine and sulfamethoxazole in an agricultural soil system under an anaerobic condition: Kinetics and environmental risks. Chemosphere, 2018, 194: 266-274

40 Engelhardt I, Sittig S, Šimůnek J, et al. Fate of the antibiotic sulfadiazine in natural soils: Experimental and numerical investigations. J Contam Hydrol, 2015, 177-178: 30-42

41 Goulas A, Sabourin L, Asghar F, et al. Explaining the accelerated degradation of ciprofloxacin, sulfamethazine, and erythromycin in different soil exposure scenarios by their aqueous extractability. Environ Sci Pollut Res, 2018, 25: 16236-16245

42 Topp E, Renaud J, Sumarah M, et al. Reduced persistence of the macrolide antibiotics erythromycin, clarithromycin and azithromycin in agricultural soil following several years of exposure in the field. Sci Total Environ, 2016, 562: 136-144

43 Volmer D A, Hui J P M. Study of erythromycin a decomposition products in aqueous solution by solid-phase microextraction/liquid chromatography/tandem mass spectrometry. Rapid Commun Mass Spectrom, 1998, 12: 123-129

44 Tang M, Gu Y, Wei D, et al. Enhanced hydrolysis of fermentative antibiotics in production wastewater: Hydrolysis potential prediction and engineering application. Chem Eng J, 2019, 391: 123626

45 Loftin K A, Adams C D, Meyer M T, et al. Effects of ionic strength, temperature, and pH on degradation of selected antibiotics. J Environ Qual, 2008, 37: 378-386

46 Mitchell S M, Ullman J L, Teel A L, et al. Hydrolysis of amphenicol and macrolide antibiotics: Chloramphenicol, florfenicol, spiramycin, and tylosin. Chemosphere, 2015, 134: 504-511

47 Zhang Z, Xie X, Yu Z, et al. Influence of chemical speciation on photochemical transformation of three fluoroquinolones (FQs) in water: Kinetics, mechanism, and toxicity of photolysis products. Water Res, 2018, 148: 19-29

48 Yan S, Song W. Photo-transformation of pharmaceutically active compounds in the aqueous environment: A review. Environ Sci-Processes Impacts, 2014, 16: 697-720

49 Werner J J, Arnold W A, McNeill K. Water hardness as a photochemical parameter: Tetracycline photolysis as a function of calcium concentration, magnesium concentration, and $\mathrm{pH}^{+}$. Environ Sci Technol, 2006, 40: 7236-7241

50 Liu H, Pu C, Yu X, et al. Removal of tetracyclines, sulfonamides, and quinolones by industrial-scale composting and anaerobic digestion processes. Environ Sci Pollut Res, 2018, 25: 35835-35844

51 Ho Y B, Zakaria M P, Latif P A, et al. Occurrence of veterinary antibiotics and progesterone in broiler manure and agricultural soil in Malaysia. Sci Total Environ, 2014, 488-489: 261-267

52 Lin Y C, Hsiao K W, Lin A Y C. Photolytic degradation of ciprofloxacin in solid and aqueous environments: Kinetics, phototransformation pathways, and byproducts. Environ Sci Pollut Res, 2018, 25: 2303-2312

$53 \mathrm{Xu} \mathrm{L}, \mathrm{Li} \mathrm{H}$, Mitch W A, et al. Enhanced phototransformation of tetracycline at smectite clay surfaces under simulated sunlight via a lewis-base catalyzed alkalization mechanism. Environ Sci Technol, 2019, 53: 710-718

54 Zhang H, Huang C H. Oxidative transformation of fluoroquinolone antibacterial agents and structurally related amines by manganese oxide. Environ Sci Technol, 2005, 39: 4474-4483

55 Martin S, Shchukarev A, Hanna K, et al. Kinetics and mechanisms of ciprofloxacin oxidation on hematite surfaces. Environ Sci Technol, 2015, 49: 12197-12205

56 Xie Y, Gu L, Mao S, et al. The role of structural elements and its oxidative products on the surface of ferrous sulfide in reducing the electronwithdrawing groups of tetracycline. Chem Eng J, 2019, 378: 122195

57 Li J, Zhao L, Huang C H, et al. Significant effect of evaporation process on the reaction of sulfamethoxazole with manganese oxide. Environ Sci Technol, 2020, 54: 4856-4864

58 Zhu C. Study on the interaction of photolysis products of tetracycline and oxy tetracycline with soil enzymes (in Chinese). Dissertation for Master's Degree. Jinan: Shandong University, 2020 [朱昶. 四环素和土霉素的光降解产物与土壤酶相互作用的研究. 硕士学位论文. 济南: 山东大学, 2020]

59 Jiao S, Zheng S, Yin D, et al. Aqueous oxytetracycline degradation and the toxicity change of degradation compounds in photoirradiation process. J Environ Sci, 2008, 20: 806-813

60 Halling-Sørensen B, Sengeløv G, Tjørnelund J. Toxicity of tetracyclines and tetracycline degradation products to environmentally relevant bacteria, including selected tetracycline-resistant bacteria. Archives Environ Contamination Toxicol, 2002, 42: 263-271 
61 Yi Q, Gao Y, Zhang H, et al. Establishment of a pretreatment method for tetracycline production wastewater using enhanced hydrolysis. Chem Eng J, 2016, 300: 139-145

62 Wu Q, Que Z, Li Z, et al. Photodegradation of ciprofloxacin adsorbed in the intracrystalline space of montmorillonite. J Hazard Mater, 2018, 359: 414-420

63 Karpov M, Seiwert B, Mordehay V, et al. Transformation of oxytetracycline by redox-active Fe(III)- and Mn(IV)-containing minerals: Processes and mechanisms. Water Res, 2018, 145: 136-145

64 Kong W D, Zhu Y G. A review on ecotoxicology of veterinary pharmaceuticals to plants and soil microbes (in Chinese). J Ecotox, 2007, 2: 1-9 [孔维栋, 朱永官. 抗生素类兽药对植物和土壤微生物的生态毒理学效应研究进展. 生态毒理学报, 2007, 2: 1-9]

65 Zhang J X, Shen G M, Kong F Y, et al. Effect of tetracycline on the growth and photosynthesis of flue-cured tobacco. J Ag-Env Sci, 2017, 36: $48-56$

$66 \mathrm{Xu}$ Q T. Pollution characteristics of typical contaminates and physiological effects of antibiotics in the soil-vegetable system (in Chinese). Dissertation for Doctoral Degree. Hangzhou: Zhejiang University, 2019 [徐秋桐. 土壤-蔬菜系统典型污染物的污染特征及抗生素的生理效 应. 博士学位论文. 杭州: 浙江大学, 2019]

67 Pan M, Chu L M. Phytotoxicity of veterinary antibiotics to seed germination and root elongation of crops. Ecotoxicol Environ Saf, 2016, 126: 228-237

68 Liu D. Tetracyclines transformation, accumulation and in vitro diagnosis model in soil-vegetable system (in Chinese). Dissertation for Doctoral Degree. Hangzhou: Zhejiang University, 2017 [刘娣. 土壤-蔬菜系统中四环素类抗生素迁移积累与污染的细胞诊断方法. 博士学位论文. 杭州: 浙江大学, 2017]

69 Bao C Y, Gu G P, Zhang M K. Effects of veterinary antibiotics stress on growth and antibiotics accumulation of Oenanthe javanica DC (in Chinese). Chin J Soil Sci, 2016, 47: 164-172 [鲍陈燕, 顾国平, 章明奎. 兽用抗生素胁迫对水芹生长及其抗生素积累的影响. 土壤通报, 2016, 47: 164-172]

70 Ahmed M B M, Rajapaksha A U, Lim J E, et al. Distribution and accumulative pattern of tetracyclines and sulfonamides in edible vegetables of cucumber, tomato, and lettuce. J Agric Food Chem, 2015, 63: 398-405

71 Azanu D, Mortey C, Darko G, et al. Uptake of antibiotics from irrigation water by plants. Chemosphere, 2016, 157: 107-114

72 Chi S L, Wang W Z, Xu W H, et al. Effects of tetracycline antibiotics on growth and characteristics of enrichment and transformation in two vegetables (in Chinese). Environ Sci, 2018, 39: 935-943 [迟荪琳, 王卫中, 徐卫红, 等. 四环素类抗生素对不同蔬菜生长的影响及其富集转 运特征. 环境科学, 2018, 39: 935-943]

73 Zhang C, Feng Y, Liu Y, et al. Uptake and translocation of organic pollutants in plants: A review. J Integrative Agr, 2017, 16: 1659-1668

74 Migliore L, Cozzolino S, Fiori M. Phytotoxicity to and uptake of enrofloxacin in crop plants. Chemosphere, 2003, 52: 1233-1244

$75 \mathrm{Wu}$ X L. Variation in rhizosphere features and their effects on the accumulation of Ciprofloxacin-(CIP) in high-and low-CIP accumulation cultivars of Chinese flowering cabbage (Brassica parachinensis L.) (in Chinese). Dissertation for Doctoral Degree. Guangzhou: Jinan University, 2017 [吴小莲. 环丙沙星(CIP)高、低累积菜心根际特性及其吸收累积影响机制. 博士学位论文. 广州: 暨南大学, 2017]

76 Dong L, Gao J, Xie X, et al. DNA damage and biochemical toxicity of antibiotics in soil on the earthworm eisenia fetida. Chemosphere, 2012, 89: 44-51

$77 \mathrm{Li} \mathrm{Y}$, Tang $\mathrm{H}, \mathrm{Hu}$ Y, et al. Enrofloxacin at environmentally relevant concentrations enhances uptake and toxicity of cadmium in the earthworm eisenia fetida in farm soils. J Hazard Mater, 2016, 308: 312-320

78 Litskas V D, Karamanlis X N, Prousali S P, et al. The xenobiotic doxycycline affects nitrogen transformations in soil and impacts earthworms and cultivated plants. J Environ Sci Health Part A, 2019, 54: 1441-1447

79 Zhu D, An X L, Chen Q L, et al. Antibiotics disturb the microbiome and increase the incidence of resistance genes in the gut of a common soil collembolan. Environ Sci Technol, 2018, 52: 3081-3090

80 Li J. Toxicological study on response of different biological level characteristics of collembolan (collembola) to heavy metals in farmland and antibiotics pollution (in Chinese). Dissertation for Doctoral Degree. Shanghai: East China Normal University, 2019 [李进. 跳虫(弹尾纲)不同生 物水平特征对农田重金属和抗生素类污染响应的毒理学研究. 博士学位论文. 上海: 华东师范大学, 2019]

81 Gao M, Lv M, Han M, et al. Avoidance behavior of eisenia fetida in oxytetracycline- and heavy metal-contaminated soils. Environ Toxicol Pharmacol, 2016, 47: 119-123

82 Hammesfahr U, Heuer H, Manzke B, et al. Impact of the antibiotic sulfadiazine and pig manure on the microbial community structure in 
agricultural soils. Soil Biol Biochem, 2008, 40: 1583-1591

83 Han L, Zhang H, Long Z, et al. Exploring microbial community structure and biological function in manured soil during ten repeated treatments with chlortetracycline and ciprofloxacin. Chemosphere, 2019, 228: 469-477

$84 \mathrm{Xu} \mathrm{K}$, Wang J, Gong H, et al. Occurrence of antibiotics and their associations with antibiotic resistance genes and bacterial communities in Guangdong coastal areas. Ecotoxicol Environ Saf, 2019, 186: 109796

85 Zhang M Q, Yuan L, Li Z H, et al. Tetracycline exposure shifted microbial communities and enriched antibiotic resistance genes in the aerobic granular sludge. Environ Int, 2019, 130: 104902

86 Fang H, Han Y, Yin Y, et al. Variations in dissipation rate, microbial function and antibiotic resistance due to repeated introductions of manure containing sulfadiazine and chlortetracycline to soil. Chemosphere, 2014, 96: 51-56

87 Wang L P. The fate of typical exterior-source antibiotics in soils and their interaction with microbial diversity (in Chinese). Dissertation for Doctoral Degree. Hangzhou: Zhejiang University, 2008 [王丽平. 典型外源抗生素在土壤中的转归及其与土壤微生物多样性的相互作用和 机理研究. 博士学位论文. 杭州: 浙江大学, 2008]

88 Ma J, Lin H, Sun W, et al. Soil microbial systems respond differentially to tetracycline, sulfamonomethoxine, and ciprofloxacin entering soil under pot experimental conditions alone and in combination. Environ Sci Pollut Res, 2014, 21: 7436-7448

89 Han L X. Residual characteristics and ecological effects of the typical pesticides and antibiotics in the soils during combined repeated treatments (in Chinese). Dissertation for Doctoral Degree. Hangzhou: Zhejiang University, 2019 [韩令喜. 典型农药与抗生素复合重复处理在土壤中的 残留特征及其生态效应. 博士学位论文. 杭州: 浙江大学, 2019]

90 Tang X, Lou C, Wang S, et al. Effects of long-term manure applications on the occurrence of antibiotics and antibiotic resistance genes (ARGs) in paddy soils: Evidence from four field experiments in south of China. Soil Biol Biochem, 2015, 90: 179-187

91 Wang L, Wang J, Wang J, et al. Distribution characteristics of antibiotic resistant bacteria and genes in fresh and composted manures of livestock farms. Sci Total Environ, 2019, 695: 133781

92 Wang L, Zhao X, Wang J, et al. Macrolide- and quinolone-resistant bacteria and resistance genes as indicators of antibiotic resistance gene contamination in farmland soil with manure application. Ecol Indicators, 2019, 106: 105456

93 Zhu D, An X L, Chen Q L, et al. Antibiotics disturb the microbiome and increase the incidence of resistance genes in the gut of a common soil collembolan. Environ Sci Technol, 2018, 52: 3081-3090

94 Wang H T, Chi Q Q, Zhu D, et al. Arsenic and sulfamethoxazole increase the incidence of antibiotic resistance genes in the gut of earthworm. Environ Sci Technol, 2019, 53: 10445-10453

95 Duan M, Gu J, Wang X, et al. Factors that affect the occurrence and distribution of antibiotic resistance genes in soils from livestock and poultry farms. Ecotoxicol Environ Saf, 2019, 180: 114-122

96 Wang P, Wu D, You X, et al. Distribution of antibiotics, metals and antibiotic resistance genes during landfilling process in major municipal solid waste landfills. Environ Pollution, 2019, 255: 113222

97 Hurst J J, Oliver J P, Schueler J, et al. Trends in antimicrobial resistance genes in manure blend pits and long-term storage across dairy farms with comparisons to antimicrobial usage and residual concentrations. Environ Sci Technol, 2019, 53: 2405-2415

98 Liang G, Wang Z, Yang X, et al. Efficient removal of oxytetracycline from aqueous solution using magnetic montmorillonite-biochar composite prepared by one step pyrolysis. Sci Total Environ, 2019, 695: 133800

99 Liao H P, Chen Z, Yu Z, et al. Development of hperthermophinic aerobic composting and its engineering applications in organic solid wastes (in Chinese). J Fujian Agriculture Forestry Univ (Nat Sci Ed), 2017, 46: 439-444 [廖汉鹏, 陈志, 余震, 等. 有机固体废物超高温好氧发酵技术及 其工程应用. 福建农林大学学报(自然科学版), 2017, 46: 439-444]

100 Zheng J L, Liu C X, Liu L, et al. Removal of antibiotics in waste and wastewater treatment facilities of animal breeding industry: A review (in Chinese). Environ Chem, 2017, 36: 37-47 [郑佳伦, 刘超翔, 刘琳, 等. 畜禽养殖业主要废弃物处理工艺消除抗生素研究进展. 环境化学, 2017, 36: 37-47]

101 Shi H L, Wang X C, Li Q. Removal of typical antibiotics during aerobic composting of human feces (in Chinese). Environ Sci, 2018, 39: 34343442 [时红蕾, 王晓昌, 李倩. 人粪便好氧堆肥过程中典型抗生素的消减特性. 环境科学, 2018, 39: 3434-3442]

102 Wang Q, Yates S R. Laboratory study of oxytetracycline degradation kinetics in animal manure and soil. J Agric Food Chem, 2008, 56: 16831688

103 Meng L, Yang B, Xue N D, et al. Effect of high temperature composting on removal of fluoroquinolones in chicken manures (in Chinese). J 
Agro-Environ Sci, 2015, 34: 377-383 [孟否, 杨兵, 薛南冬, 等. 高温堆肥对鸡粪中氟喹诺酮类抗生素的去除. 农业环境科学学报, 2015, 34: 377-383]

104 Feng L, Casas M E, Ottosen L D M, et al. Removal of antibiotics during the anaerobic digestion of pig manure. Sci Total Environ, 2017, 603604: $219-225$

$105 \mathrm{Hu} \mathrm{Z}$, Liu Y, Chen G, et al. Characterization of organic matter degradation during composting of manure-straw mixtures spiked with tetracyclines. Bioresource Tech, 2011, 102: 7329-7334

106 Yang B, Meng L, Xue N. Removal of five fluoroquinolone antibiotics during broiler manure composting. Environ Tech, 2018, 39: 373-381

107 Withey J M, Mugo S M, Zhou T, et al. Depletion of hormones and antimicrobials in cattle manure using thermophilic anaerobic digestion. J Chem Technol Biotechnol, 2016, 91: 2404-2411

108 Guo R, Li G, Jiang T, et al. Effect of aeration rate, C/N ratio and moisture content on the stability and maturity of compost. Bioresource Tech, 2012, 112: 171-178

109 Munaretto J S, Yonkos L, Aga D S. Transformation of ionophore antimicrobials in poultry litter during pilot-scale composting. Environ Pollution, 2016, 212: 392-400

110 Yuan J, Chadwick D, Zhang D, et al. Effects of aeration rate on maturity and gaseous emissions during sewage sludge composting. Waste Manage, 2016, 56: 403-410

111 Xiao L, Huang Y M, Zhao J F, et al. Effects of exogenous microbial agents on pig manure compost quality and tetracycline antibiotic degradation (in Chinese). J Agro-Environ Sci, 2016, 35: 172-178 [肖礼, 黄懿梅, 赵俊峰, 等. 外源菌剂对猪粪堆肥质量及四环素类抗生素降 解的影响. 农业环境科学学报, 2016, 35: 172-178]

112 Li W M, Bao Y Y, Zhou Q X. Degradation pathways and main degradation products of tetracycline antibiotics: Research progress (in Chinese). Chin J Appl Ecol, 2012, 23: 2300-2308 [李伟明, 鲍艳宇, 周启星. 四环素类抗生素降解途径及其主要降解产物研究进展. 应用生态学报, 2012, 23: 2300-2308]

113 Qiu T L, Gao M, Han M L, et al. Decreases of tetracyclines and antibiotics-resistant bacteria during composting of chicken manure (in Chinese). J Agro-Environ Sci, 2015, 34: 795-800 [仇天雷, 高敏, 韩梅琳, 等. 鸡粪堆肥过程中四环素类抗生素及抗性细菌的消减研究. 农业环境科学 学报, 2015, 34: 795-800]

114 Mohring S A I, Strzysch I, Fernandes M R, et al. Degradation and elimination of various sulfonamides during anaerobic fermentation: A promising step on the way to sustainable pharmacy? Environ Sci Technol, 2009, 43: 2569-2574

115 Álvarez J A, Otero L, Lema J M, et al. The effect and fate of antibiotics during the anaerobic digestion of pig manure. Bioresource Tech, 2010, 101: $8581-8586$

116 Loke M L, Jespersen S, Vreeken R, et al. Determination of oxytetracycline and its degradation products by high-performance liquid chromatography-tandem mass spectrometry in manure-containing anaerobic test systems. J Chromatography B, 2003, 783: 11-23

117 Varel V H, Wells J E, Shelver W L, et al. Effect of anaerobic digestion temperature on odour, coliforms and chlortetracycline in swine manure or monensin in cattle manure. J Appl MicroBiol, 2012, 112: 705-715

118 Turker G, Aydin S, Akyol Ç 1, et al. Changes in microbial community structures due to varying operational conditions in the anaerobic digestion of oxytetracycline-medicated cow manure. Appl Microbiol Biotechnol, 2016, 100: 6469-6479

119 Al-Ahmad A, Daschner F D, Kummerer K. Biodegradability of cefotiam, ciprofloxacin, meropenem, penicillin G, and sulfamethoxazole and inhibition of waste water bacteria. Archives Environ Contamination Toxicol, 1999, 37: 158-163

120 Nurk L, Knörzer S, Jacobi H F, et al. Elimination of sulfonamides and tetracyclines during anaerobic fermentation-A "Cheshire Cat" phenomenon. Sustain Chem Pharmacy, 2019, 13: 100157

121 Cui Y N, Zhang X H, Liu X Y, et al. Effects of different swine manure treatments on growth, yield and quality of cabbage (in Chinese). J Nanjing Agricultural Univ, 2017, 40: 281-286 [崔亚男, 张旭辉, 刘晓雨, 等. 不同猪粪施用方式对小白菜生长, 产量及品质的影响. 南京农 业大学学报, 2017, 40: 281-286]

122 Zhou X, Qiao M, Su J Q, et al. Turning pig manure into biochar can effectively mitigate antibiotic resistance genes as organic fertilizer. Sci Total Environ, 2019, 649: 902-908

123 Li C, Xie S, Wang Y, et al. Simultaneous heavy metal immobilization and antibiotics removal during synergetic treatment of sewage sludge and pig manure. Environ Sci Pollut Res, 2020, 27: 30323-30332

124 Tian R, Li C, Xie S, et al. Preparation of biochar via pyrolysis at laboratory and pilot scales to remove antibiotics and immobilize heavy metals 
in livestock feces. J Soils Sediments, 2019, 19: 2891-2902

125 Pruden A, Larsson D G J, Amézquita A, et al. Management options for reducing the release of antibiotics and antibiotic resistance genes to the environment. Environ Health Perspectives, 2013, 121: 878-885

126 Li J, Pan L, Yu G, et al. The synthesis of heterogeneous Fenton-like catalyst using sewage sludge biochar and its application for ciprofloxacin degradation. Sci Total Environ, 2019, 654: 1284-1292

127 Han Y, Duo L A, Liu Z Q, et al. Fractionated extraction and characterization of biochar and its adsorption behavior for sulfamethoxazole (in Chinese). Acta Sci Circumst, 2017, 37: 2181-2189 [韩旸, 多立安, 刘仲齐, 等. 生物炭颗粒的分级提取、表征及其对磺胺甲噁唑的吸附性 能研究. 环境科学学报, 2017, 37: 2181-2189]

128 Jeong C Y, Wang J J, Dodla S K, et al. Effect of biochar amendment on tylosin adsorption-desorption and transport in two different soils. J Environ Qual, 2012, 41: 1185-1192

129 Zhang H Y, Wang Z W, Gao J H, et al. Adsorption characteristics of norfloxacin by biochars derived from reed straw and municipal sludge (in Chinese). Environ Sci, 2016, 37: 689-696 [张涵瑜, 王兆炜, 高俊红, 等. 芦苇基和污泥基生物炭对水体中诺氟沙星的吸附性能. 环境科学, 2016, 37: 689-696]

130 Wang L, Chen G, Owens G, et al. Enhanced antibiotic removal by the addition of bamboo charcoal during pig manure composting. RSC Adv, 2016, 6: 27575-27583

131 Zeng Z W, Tan X F, Liu Y G, et al. Comprehensive adsorption studies of doxycycline and ciprofloxacin antibiotics by biochars prepared at different temperatures. Front Chem, 2018, 6: 80

132 Cheng Y, Shen Q B, Liu Z D, et al. Preparation of two kinds of biochar and the factors influencing tetracycline removal from aqueous solution (in Chinese). Environ Sci, 2019, 40: 1328-1336 [程扬, 沈启斌, 刘子丹, 等. 两种生物炭的制备及其对水溶液中四环素去除的影响因素. 环 境科学, 2019, 40: 1328-1336]

133 He J, Dai J, Zhang T, et al. Preparation of highly porous carbon from sustainable $\alpha$-cellulose for superior removal performance of tetracycline and sulfamethazine from water. RSC Adv, 2016, 6: 28023-28033

134 Li T, Han X, Liang C, et al. Sorption of sulphamethoxazole by the biochars derived from rice straw and alligator flag. Environ Tech, 2015, 36: $245-253$

135 Lian F, Sun B, Chen X, et al. Effect of humic acid (HA) on sulfonamide sorption by biochars. Environ Pollution, 2015, 204: 306-312

136 Yang Z, Xing R, Zhou W. Adsorption of ciprofloxacin and $\mathrm{Cu}^{2+}$ onto biochars in the presence of dissolved organic matter derived from animal manure. Environ Sci Pollut Res, 2019, 26: 14382-14392

137 Sun B, Lian F, Bao Q, et al. Impact of low molecular weight organic acids (LMWOAs) on biochar micropores and sorption properties for sulfamethoxazole. Environ Pollution, 2016, 214: 142-148

138 Li R N, Wang Z W, Guo J L, et al. Adsorption characteristics of sulfathiazole in aqueous solution by acid/alkali modified biochars (in Chinese). Acta Sci Circumst, 2017, 37:4119-4128 [李荵宁, 王兆炜, 郭家否, 等. 酸碱改性生物炭对水中磺胺噻唑的吸附性能研究. 环境科学学报, 2017, 37: 4119-4128]

139 Luo J P, Fang R, Shi J J, et al. Adsorption performance of tetracycline on nitric acid-modified rape biochar (in Chinese). Environ Sci Technol, 2019, 32: 21-27 [骆俊鹏, 方茹, 史娟娟, 等. 硝酸改性油菜生物炭对四环素的吸附性能研究. 环境科技, 2019, 32: 21-27]

140 Zhou Y, Liu X, Xiang Y, et al. Modification of biochar derived from sawdust and its application in removal of tetracycline and copper from aqueous solution: Adsorption mechanism and modelling. Bioresource Tech, 2017, 245: 266-273

141 Jiang B, Lin Y, Mbog J C. Biochar derived from swine manure digestate and applied on the removals of heavy metals and antibiotics. Bioresource Tech, 2018, 270: 603-611

142 Guo X, Dong H, Yang C, et al. Application of goethite modified biochar for tylosin removal from aqueous solution. Colloids Surfs APhysicochem Eng Aspects, 2016, 502: 81-88

143 Wang F, Ma S, Si Y, et al. Interaction mechanisms of antibiotic sulfamethoxazole with various graphene-based materials and multiwall carbon nanotubes and the effect of humic acid in water. Carbon, 2017, 114: 671-678

144 Gao Y, Li Y, Zhang L, et al. Adsorption and removal of tetracycline antibiotics from aqueous solution by graphene oxide. J Colloid Interface Sci, 2012, 368: 540-546

145 Jiang Z, Yu F, Ma J. Design of graphene-based adsorbents and its removal of antibiotics in aqueous solution (in Chinese). Acta Physico-Chim Sin, 2019, 35: 709-724 [姜哲, 于飞, 马杰. 石墨烯基吸附剂的设计及其对水中抗生素的去除. 物理化学学报, 2019, 35: 709-724] 
146 Yang Y, Hu X, Zhao Y, et al. Decontamination of tetracycline by thiourea-dioxide-reduced magnetic graphene oxide: Effects of pH, ionic strength, and humic acid concentration. J Colloid Interface Sci, 2017, 495: 68-77

147 Yao Q, Fan B, Xiong Y, et al. 3D assembly based on 2D structure of cellulose nanofibril/graphene oxide hybrid aerogel for adsorptive removal of antibiotics in water. Sci Rep, 2017, 7: 45914

148 Huang D, Wang X, Zhang C, et al. Sorptive removal of ionizable antibiotic sulfamethazine from aqueous solution by graphene oxide-coated biochar nanocomposites: Influencing factors and mechanism. Chemosphere, 2017, 186: 414-421

\title{
Veterinary antibiotics in soils: Environmental processes, ecotoxicity, and risk mitigation
}

\author{
WANG XiaoJie ${ }^{1,2,3}$, ZHAO $\mathrm{Wei}^{2}$, ZHANG ZhiChao ${ }^{2}$, CHENG $\mathrm{HeFa}^{2}$ \& TAO Shu ${ }^{2}$ \\ ${ }^{1}$ State Key Laboratory of Organic Geochemistry, Guangzhou Institute of Geochemistry, Chinese Academy of Sciences, Guangzhou 510640, China; \\ ${ }^{2}$ MOE Laboratory for Earth Surface Processes, College of Urban and Environmental Sciences, Peking University, Beijing 100871, China; \\ ${ }^{3}$ University of Chinese Academy of Sciences, Beijing 100049, China
}

Concentrated animal feeding operations have long extensively used antibiotics to prevent and treat infectious animal diseases and promote the growth of farmed animals, which have resulted in discharges of large quantities of un-metabolized veterinary antibiotics into agricultural soils along with the land application of animal manure. These veterinary antibiotics in soils could exert a range of ecotoxicological effects and even induce the emergence and development of antimicrobial-resistant microbes and genes, which pose a potential threat to human health. This review provides a systematic overview of the transport and fate processes of antibiotics in the soil environment and the corresponding mechanism, their ecotoxicological effects on crops, soil fauna, and soil microorganisms, and the strategies that can be used to mitigate the risk of antimicrobial pollution and the related mechanism. The major environmental processes of antibiotics in soil, including adsorption/desorption, biodegradation, and abiotic degradation, all strongly depend on the soil's physical and chemical properties (e.g., $\mathrm{pH}$ and organic matter content) and the chemical structures and properties of antibiotics (e.g., functional group and hydrophobicity). The ecotoxicological effects of veterinary antibiotics on crops, soil fauna, and soil microorganisms are mainly determined by their types and concentrations and the soil's physical and chemical properties. Antibiotic degradation during manure composting and anaerobic digestion primarily occurs through biodegradation and hydrolysis. The antibiotics in manure can be effectively degraded by high-temperature pyrolysis. In addition, biochar and graphene-based composite materials can stabilize the antibiotics in soils through hydrogen bonding, surface complexation, electrostatic interaction, and ion exchange. Important questions that must be addressed and recommendations for future research are proposed herein based on the summary of the recent research progresses on soil pollution by antibiotics.

agricultural soils, veterinary antibiotics, adsorption/desorption, degradation, ecotoxicological effects, risk mitigation

doi: 10.1360/SST-2020-0337 